\title{
Care Provision: An Experimental Investigation
}

\author{
By Sheheryar Banuri, Angela C. M. de Oliveira and Catherine C. Eckel*
}

March 2018

\begin{abstract}
In many principal-agent settings, the effort provided by the agent benefits a third party, such as a client or customer who is in need of care. In these settings the worker's pro-social motivations can substantially impact the quality of the product or service and the well-being of the client. We capture this setting by expanding the classic trust game to include three players: a principal, an agent, and a recipient who requires care. The principal can transfer resources to an agent, trusting the agent to then transfer resources to the needy recipient; the latter transfers are tripled. As in the two-player version, we find high, but variable, levels of trust and pay-it-forward reciprocity (agent transfers to target) in the baseline game. Two treatments mimic potential policy interventions intended to improve the level of care. The first provides a budget subsidy to the principal, and the second alters the effectiveness (multiplier) of the agent's transfers. Results show that the behavior of the agent does not vary by treatment, and is determined primarily by the amount received from the principal. Principals, on the other hand, do respond to the policy changes. Subsidies have little impact on the care recipient, but policies impacting the agent's efficiency increase the amount entrusted to them by principals and significantly impact the well being of the recipient. Results suggest that policies that increase the effectiveness of care workers (the agents), such as include increased worker training and reductions in administrative burden, may significantly impact the quality of work provided.
\end{abstract}

* Banuri: University of East Anglia, Arts 3.49 (email: s.banuri@uea.ac.uk); de Oliveira, Department of Resource Economics, University of Massachusetts Amherst, 203 Stockbridge Hall, 80 Campus Center Way, Amherst, MA 01003 (email: adeolive@resecon.umass.edu); Eckel (corresponding): Department of Economics, Texas A\&M University, 4228 TAMU, College Station, TX 77845 (email: ceckel@tamu.edu).

Acknowledgements: We are grateful to Paula England and Nancy Folbre for comments and encouragement at the inception of this project. Wendy Lee, Elizabeth Pickett, Ericka Scherenberg Farret, Abdul Kidwai and Lee Stroman provided valuable research assistance at various stages of the research project. Additionally, we thank members of the Working Group on Care at the Russell Sage Foundation, as well as participants at the Allied Social Science Association annual meetings, Science of Philanthropy annual meetings, Economic Science Association North American Regional meetings and Southern Economic Association annual meetings for valuable feedback. Funding was provided by the Russell Sage Foundation and the National Science Foundation SES-1062027, SES-1062055 and SES-1344018.

Keywords: Trust game, social preferences, care work, lab experiment

JEL Codes: C91, D1, J4 


\section{Care Provision: An Experimental Investigation}

\section{Introduction}

In many principal-agent settings, the effort provided by the agent benefits a third party, such as a client or customer who is in need of care. In these settings, the quality of the product or service delivered to the client is determined, at least in part, by the worker's effort. Workers are motivated not only by monetary incentives, and non-monetary motivations have been linked to the worker's pro-social preferences or the extent to which workers' own preferences align with the firm's mission. While training and worker skill are fundamental to the quality of the work provided, for many professions the desire to 'do good' also impacts service quality and client well-being. As examples, consider educators, police officers, and public servants. In all of these professions, the motivation to contribute to the mission and help others impacts quality.

These professions also involve an element of trust in the agents on behalf of the principal: neither the motivations of the agents nor the quality of their work are directly observable or contractible. Appropriate policy design in settings where pro-social motivations play an important role remains an important theoretical and empirical challenge. We contribute to the discussion by providing evidence from controlled laboratory experiments. By extending the classic trust game, we develop a simple three-person game where a principal contracts with an agent to care for a needy client. We then use this game to gauge the reactions of motivated principals and agents to potential policy interventions.

While our three-person game can apply to a broad range of settings, in this paper we focus on a single application, care work. The term "care work" is used to refer to the work of caring for others, including both paid and unpaid care. Care work includes caring for children as well as taking care of the sick and elderly, and encompasses a variety of skill levels (e.g. from 
nurse's aid to physician) and a range of professions including health care of all types, and all

levels of teaching. Non-monetary motivations (social preferences in particular) are considered to play a critical role in the choice of a care profession (Dur and Zoutenbier 2015) or in the provision of high quality care (Folbre 2012).

Care work is an important and growing component of the economy. As the population ages, a larger portion requires care, either through the formal sector, or informally through family and friends. Approximately $24 \%$ of the workforce are currently employed in care professions ( $16 \%$ of workers provide interactive, hands-on care), and the effort to provide care to the sick and the elderly is due to take up an increasing share of the workforce (Folbre 2012; England and Folbre 2003). In Europe, the World Health Organization has noted the "difficulties of creating and maintaining an effective, efficient and motivated workforce" as a key issue in the care sector (p. 1, Dubois, McKee and Rechel 2006).

We develop the first "experimental model" of the care sector, focusing on the organization of work, and use it to test the impact of two potential policy interventions: budget subsidies to care managers, and training to enhance the effectiveness of workers. We follow a long tradition in experimental economics of using the lab as a testbed: experiments are particularly useful in testing the impact of such policies on a small scale prior to implementation, or when field experiments would be costly or risky. ${ }^{1}$

\footnotetext{
${ }^{1}$ Lab experiments have long been used to develop experimental models of key policy settings and for "wind tunnel" or "test bed" demonstrations of the impact of policy alternatives. In their widely-used text, Friedman and Sunder (1994) discuss the purposes of experiments, and claim: "One scientific purpose is to discover empirical regularities in areas for which existing theory has little to say." (p. 8). That is, experiments can be used to simulate, or model, key aspects of a market, and thereby to generate data on regularities in behavior which can then be used for theory development. They cite many examples. This claim echoes Plott's (1982) argument that: "In circumstances in which a policy is going to be imposed on a social system, simulation objectives involve an attempt to recreate the situation on a smaller scale in order to provide decision makers with some experience with how the situation might evolve." (p. 1521). Thus experiments have been used to model a wide variety of settings, including auctions, markets, public goods, computer-assisted markets, and others, in order to generate data that can be used as
} 
In the formal care sector, a team of care workers is employed by a manager or organization to provide care to a needy recipient. In the informal sector, it is often the case that a single responsible person (a relative) engages in a transaction with a similar structure, employing a worker to care for a needy family member. Our game consists of a principal (care manager), agent (care worker), and a needy recipient, and mimics the typical organization of work in the care sector. The game is constructed so that a care worker can provide care more efficiently (at lower cost) than the care manger. The manager can accomplish this by transferring resources to the care worker, and "trusting" him to provide care to the recipient. The care manager either can transfer resources directly to the recipient (where one unit transferred produces one unit of benefit), or can send resources to the care worker who can then transfer resources to the recipient at a lower cost (where one unit transferred produces three units of benefit). We then gauge the impact of two policies by comparing two treatments with the baseline game.

The decision to become a care worker is typically thought to entail some degree of social preference motivation; that is, individuals choose a career in the care sector because they have a preference for helping others (see e.g., England 2005; England et al. 2002; Dur and Zoutenbier 2015). Care workers generally earn significantly less than equivalently-skilled counterparts in the non-care sector (see Folbre 2012, and the references therein). Within the care sector, individuals who work in nonprofit environments earn less than those who work in for-profit environments (e.g., Serra et al. 2011). Theories of 'motivated agents,' along with the theory of compensating differentials, imply that the relatively low wages observed in the sector must be coupled with correspondingly high levels of intrinsic reward (Akerlof and Kranton 2005, 2011; Benabou and Tirole 2003, 2006; Besley and Ghatak 2005; Banuri and Keefer 2016). Furthermore, this controlled setting. 
relationship involves trust: monitoring is imperfect at best, making complete contracts based on the quality of care difficult or impossible to construct, and the manager must trust the care worker to take care of the elderly, ill, or disabled person. The trust issue is compounded since care services tend to be customized to the recipient rather than standardized (Folbre 2008). The importance of trust also implies that the quality of care work depends not just on the workers' training, but also on their pro-social preferences.

The care market has substantial policy relevance as the 'baby boomer' generation population ages. It is therefore vital to understand the impact of alternative policies in this market. One way to begin to address these questions is through lab experiments designed to capture the key elements of the setting. Testing the potential response to policy changes can begin in the lab at a relatively low cost, and the results of these experiments can provide information for designing more costly field experiments or trials. However, due to the dependency of the care recipients, who may not be able to advocate on their own behalf, randomized trials and natural experiments (which would provide the cleanest evaluation of the response of individuals and their families in this setting) also may carry serious ethical concerns. Further, the quality of care is notoriously difficult to measure.

We consider two types of potential policy interventions. The first is a direct subsidy to care managers. Families, particularly low-income families, face a number of unappealing choices in arranging care for their loved ones: elderly parents who require care may move in with relatives or into a means-tested Medicaid nursing home. In the US some state Medicaid programs, like Cash and Counseling, a consumer directed care program, allow care recipients to select a home care agency, or even to select family members, to receive direct payment for care 
services or subsidies to assist in providing for their care. ${ }^{2}$ More comprehensive versions of consumer-directed care programs have been implemented in the UK, Netherlands, and Germany (e.g., Arntz and Thomsen 2011; Kodner 2003). We capture this policy in the lab using a direct subsidy or "budget" for care given to the care manager.

Second, we consider policies that may enhance worker productivity. On the supply side of the market, the effectiveness of care workers is impacted by a number of factors. These factors can be positive, as with specific types of training workers receive (Burke et al. 2006; Nicol et al. 2005) or the organizations' commitment to safety (Gershon et al. 1995). They also can be negative, like the level of occupational stress and burnout (Felton 1998; Landsbergis 1988). In the experiments, we capture policies that increase worker effectiveness by directly manipulating their productivity, as explained below.

Our experimental 'model' of the care sector setting provides a baseline for evaluating various aspects of the care sector, and for investigating the impact of alternative policies. We take advantage of natural variation in social preferences on the part of the care worker to assess the variable impact of potential policies. The policies we address vary the budget available for care (like the consumer-directed care programs), and vary the effectiveness of the care worker (representing the potential impact of appropriate training and support on care worker effectiveness). In our game, needy individuals are unable to make their own decisions, and the care worker is more effective (productive) than the family member, but has a less-direct relationship with the care recipient. The variation in behavior provides some insight into the relationship between care-worker motives and the well being of the care recipient.

Our baseline shows that care managers tend to choose to provide care both directly and

\footnotetext{
2 These programs vary significantly by locality (e.g., Kodner 2003; Phillips and Schneider 2007).
} 
through the care worker, and care workers are for the most part responsible caretakers, reciprocating the manager's care with "pay it forward" reciprocity. We also find that the most effective policy interventions involve improvements in the effectiveness of the care worker rather than direct subsidies.

\section{Previous Literature}

This study lies at the intersection of two main lines of research. First, we discuss the literature on worker motivation, which has been the target of considerable theoretical and empirical investigation. In addition, we discuss existing empirical research on two types of policy interventions, consumer-controlled subsidies and factors influencing effective care.

\subsection{Social Preferences \&Non-Monetary Motivations}

In a variety of settings, individuals behave pro-socially, making decisions that improve the welfare of others at a significant personal cost (Fehr et al. 1996; Fehr et al. 1998; Fehr and Fischbacher 2002; Gächter et al. 2011; Camerer 2003 provides a review). For helping professions such as care workers, there is reason to believe that employers (in our setting, care managers) benefit from hiring workers who are pro-socially oriented and whose intrinsic motivation is aligned with the agent's goals (Besley and Ghatak 2005). However, designing incentive contracts in situations like this is not trivial (Bénabou and Tirole 2003, 2006; Carpenter et al. 2010). Many studies find that rewards or incentives can be detrimental because they reduce motivation (Deci, Koestner and Ryan 1999; Frey 1993), and others show that non-financial rewards can be more effective than financial rewards for motivating workers (Ashraf, Bandiera, and Jack 2014).

In our experimental model, we capture this element of the care sector by limiting the care 
manager's ability to contract with a care worker for specific outcomes or behaviors. The manager can observe the worker's effort in the game, but is unable to contract on that basis. Thus while we do not explicitly focus on the role of incentives in this study, we lay the groundwork for future exploration of the impact of incentive contracts. Further, we examine the role of nonmonetary motivation in our care model, absent rewards and punishments. Our setting is a threeplayer trust game, where a care manager can provide care directly but inefficiently, or can trust a third party to provide care more efficiently.

In the classic dyadic trust game (Berg et al. 1995) a first mover determines the size of the "pie" by transferring resources (which are multiplied on the way) to a second mover, who then decides the distribution of the pie. A second mover who is interested only in his own payoffs will keep any resources given to him, with his failure to reciprocate thereby discouraging the firstmover's trust. Experiments testing this game find considerable trust, however, with first movers transferring on average about half of their endowments, and second movers repaying their trust (Johnson and Mislin 2011 provide a meta-analysis). Thus the second movers are motivated to reciprocate the first-mover's trust by something other than their own earnings. Importantly, the extent of trust strongly affects the degree of reciprocity, with second-movers returning a higher fraction of the pie as they are trusted more. This implies that the motivation to reciprocate is strengthened in the presence of greater trust. Variants of this game have been used to examine social capital (Karlan 2005), gender and culture (Croson and Buchan 1999; Bohnet et al., 2008), intergroup trust (Heap et al., 2009), and incentive contacts (Rigdon 2009; Ben Ner and Putterman 2009) among many other applications.

The gift-exchange game (Akerlof 1982) has a similar strategic structure, where a first mover transfers a gift to a second mover whose costly effort choice then determines the final 
payoffs of the two players. These games have been adapted to mimic the principal-agent situation, where an employer must decide how much to trust a worker whose effort determines the distribution of resources (e.g., Fehr et al. 1998). ${ }^{3}$ As in the trust game, higher effort is observed with higher wages.

As in the second stage of the standard trust game, the final stage of our setting also has the flavor of the dictator game, where one player, the dictator, controls the allocation of a fixed endowment between himself and another player, and a self-interested player will keep the endowment for himself (Forsythe et al. 1994). But behavior in lab experiments reveals considerable generosity (summarized in Camerer 2003 Chapter 2). Even when the experiment is 'double blind' (neither the recipient nor the experimenter know the amount of an individual's gift), only about 60 percent of student subjects keep the entire endowment (Hoffman et al. 1994); this provides a kind of lower-bound measure of pro-socially-motivated giving. This game is known for its sensitivity: dictator game giving can vary from an equal division (Carpenter et al. 2005; Eckel et al. 2011) to almost complete selfishness (Cherry et al. 2002; List 2007; Bardsley 2008) depending on how it is framed and implemented. Other non-monetary motivations also play an important role: the more "deserving" the recipient the greater the size of the transfer (e.g., Eckel and Grossman 1996).

Several scholars have developed three-person trust games to address particular issues. Cassar and Ridgon (2011) examine peer effects in trust and trustworthiness by creating two games, one with a single sender and two receivers and a second with two senders and one receiver. They find that perceptions of trust depend on what is happening on the other node of

\footnotetext{
${ }^{3}$ See also Charness et al. 2004 for a more skeptical perspective.
} 
the game: trusting behavior is seen as relative rather than absolute. ${ }^{4}$ Rietz et al. (2013) and Sheremeta and Zhang (2014) expand the game by introducing an intermediary, creating a setting with an investor, an intermediary, and a borrower. The former examines transparency in this setting, while the latter introduces two-way communication. Both find increased efficiency resulting from enhanced information (whether transparency or communication) at the second phase of the game. Thus, previous research has established the existence of trust and reciprocity extend to larger group sizes, and shows that behavior is sensitive to both financial incentives and information about group members.

In contrast, we consider a type of 'pay it forward' reciprocity, which is similar to the indirect reciprocity of Greiner and Levati (2005), but differs fundamentally in that our needy recipient is a passive beneficiary, unable to reciprocate. More specifically, a care recipient can receive resources either directly from the care manager, in a relationship like that captured by the dictator game, or via a care worker, whose relationship with the manager is akin to the trust or gift-exchange game. In our setting, any contributions to the care recipient, either from the care manager/family member or from the care worker are based on non-monetary motivation, by construction. A financially self-interested, payoff-maximizing individual would never provide care in our finitely-repeated setting. Since our experimental design utilizes anonymous groups, this allows us to identify a lower bound on the level of care based solely on non-monetary motivations such as social preferences.

\subsection{Policy Interventions}

The first policy area we consider is consumer directed care. While consumer directed

\footnotetext{
${ }^{4}$ Bigoni et al. (2013) also utilize a trust game with one sender and two receivers. However, the payoffs of all three are interdependent and vary depending on how many of the receivers choose to reciprocate. When coordinated reciprocity pays off, both receivers are more likely to be trustworthy.
} 
care programs vary widely by state and country, all are based on the premise of giving more choices to care recipients (see Kodner 2003 for an international review). One of the most flexible programs in the US, Cash and Counseling, allows eligible recipients to hire relatives and set their wages, but also allows for other care-related purchases, like modifying the recipient's home or car. Care recipients can either manage services themselves, or they can appoint a representative to do so on their behalf (Phillips and Schneider 2007). ${ }^{5}$ Consumer direction programs have been shown to increase access to formal care and overall satisfaction with care (Carlson et al. 2007).

For example, Arntz and Thomsen (2011) describe two consumer-directed care programs that are part of the Long-Term Care Insurance (LTCI) in Germany. The first, which they refer to as "cash payments," gives individuals a low amount of money (about half of what is needed for agency-directed care), but this amount can be used in any manner they choose, including informal care and payments to relatives. The second, which they refer to as "personal budgets," gives individuals the monetary equivalent of agency-based care (which may be at-home), but the use of funds is restricted to formal care services. Between 2004 and 2008, a number of individuals were randomly assigned to receive either the cash payments or personal budgets. This study finds increases in the amount of formal care received by individuals who do not have access to adequate informal care. However, for those recipients who do have access to informal care and switch to the higher personal budgets, they find that hours of care provided by relatives falls more than formal care hours increase, leading to an overall reduction in the total hours of care at a higher cost. While formal care may come at a higher direct cost than informal care, the effect on overall social welfare is ambiguous. Care by family members can carry a high

\footnotetext{
${ }^{5}$ Consumer Direction programs have been implemented in some form almost all states in the US (Spillman et al. 2006) but exact program and eligibility details vary widely across states.
} 
opportunity cost (Bolin, Lindgren and Lundborg 2008; Ettner 1996).

In our abstract setting, we consider a simplified form of consumer direction where the care manager/family member can either provide care directly or through the formal care sector. The lab gives us the flexibility to vary the subsidy to care managers, including treatments for no care budget subsidy, a low subsidy or a high subsidy. This budget subsidy can be allocated in any manner, including being kept by the family member (as would be the case if they were being paid by the care recipient).

\subsection{Effectiveness of Care}

The effectiveness of care workers depends on many factors. Some are obvious, such as the level and type of training that workers receive. Not surprisingly, individuals who receive better training are better able to care for and comfort their charges, and to implement health and safety measures, and thus provide higher quality care (Burke et al. 2006; Nicol et al. 2005). Care workers with access to better technology are also more effective. For example, those with appropriate lift and transfer technology are better able to serve their clients and simultaneously reduce back and shoulder pain and fatigue, and increase perceived safety (Yassi et al. 2001). Changes in internal policies such as an organization's commitment to safety (Gershon et al. $1995)$ and the presence of role models who appropriately implement these safety policies (Lankford et al. 2003) also can positively impact the effectiveness of care workers.

Some factors that impact care worker effectiveness are less obvious. In addition to training and direct support for care-related activities, care workers need to be appropriately cared for. When care workers receive adequate medical care, like influenza vaccinations, they miss fewer days of work and are better able to do their jobs (Yassi et al. 1991). Effectiveness is negatively impacted by occupational stress, mostly from high workload with low autonomy and 
burnout (Felton 1998; Landsbergis 1988).

In our abstract setting, we implement changes in care worker effectiveness by multiplying the contribution (level of effort/care) provided by the care worker to the care recipient. Higher multipliers indicate more effective care, while lower multipliers indicate less effective care. The lab setting allows us to examine the net benefits of such changes, and the distribution of benefits between the manager, worker and care recipient. Our base assumption is that because of the specialized training they receive and the opportunity cost of the care manager's/family member's time, even the less-effective care workers are more effective than care managers/family members at providing care. While this assumption is not universally accurate, the setting where the care manager or family member is both more motivated and more effective is not inherently interesting for an experimental study.

\section{Experimental design}

We now turn to the experimental setting. In much the same manner as formal theoretical models, when creating an experimental model one seeks parsimony: the goal is to provide the simplest possible environment that captures the key elements of the corresponding field settings that are our focus. Once this baseline is achieved, layers of complexity can be added and evaluated. ${ }^{6}$ For interested readers, the implications of different models pro-social motivations for behavior in our setting are discussed in Online Appendix A.

\subsection{Care Game Design}

The care game consists of three players. The first player, which we refer to as Person A, is the principal or care manager. For the care sector, $\mathrm{A}$ is analogous to an individual who must decide how to provide for an elderly or disabled family member. It is A's responsibility to

\footnotetext{
${ }^{6}$ While this game was designed to examine the impact of different policies on pro-social care provision behavior, it was not designed to fully test between different theories of pro-sociality. That is, we rely on a general utility function that includes both own- and other-well-being, but do not test the functional form of utility.
} 
provide care for the needy recipient, and persons in that position often have a vested interest in doing so. The second player, B, is the agent or care worker. B is analogous to a skilled worker who may or may not be hired to provide care. The third player, $\mathrm{C}$, is the needy care recipient. Participants are randomly allocated to one of these three roles. The game, described in more detail below, is summarized in Figure 1. Additional details are available in Online Appendix Figure A1. Note, the instructions used the neutral "A" or "Person A" rather than framed titles or roles.

\section{[Figure 1]}

Each participant receives a 10-token endowment. However, subjects are told that C experiences a 'bad event' and loses his/her 10 tokens. In this way, we create a needy recipient whose welfare is lower through no fault of his own. Without "care," in the form of resources transferred from A or B, C will leave the experiment without earning anything in the game.

In order to capture the relationship between the care manager and recipient, we adopt a specific frame for A's role in the game. All players are told that it is "A's responsibility" to take care of C. This language was used to create an obligation, akin to an individual's responsibility to care for a family member. The using the term 'responsible' could be seen as introducing an "experimenter demand" effect. This was done intentionally to induce a sense of obligation and a social cost to not providing care. This effect is designed to be a lower bound on social costs: a subject likely feels much less obligation to an experimenter than to a family network.

Person A can provide direct or informal care by sending tokens directly to $\mathrm{C}$ at a relatively high cost; or can provide indirect or formal care by sending tokens to $\mathrm{B}$, who can in turn send tokens to C at a lower cost. Because A cannot contract for B's behavior, there is some risk that B will fail to fulfill his role. These tokens can be allocated from A's starting 
endowment, or, if it is available, they can come out of the 'care budget' (described below). Importantly, A is not forced to provide for $\mathrm{C}$, just as not all family members contribute to the care of an elderly parent. In this baseline experiment, the individuals involved are anonymous, and thus results should be considered a lower bound on altruistic behavior. To represent the fact that care managers frequently have a partially-selfish (or structural) interest in providing quality care, A also earns a small kick-back, based on the quality of care $\mathrm{C}$ receives. This kick-back is not large enough to change the incentive structure of the game, as discussed below.

Every token $\mathrm{A}$ sends to $\mathrm{C}$ is worth 1 token to $\mathrm{C}$ : This is a direct transfer and simulates the care manager giving direct care, with a high opportunity cost. Every token A sends to B is worth 1 token to B: B then decides how many tokens, if any, to send to C. Importantly, B can deliver tokens to $\mathrm{C}$ at a lower cost, reflecting the higher effectiveness of trained workers. Each token that $\mathrm{B}$ gives up produces more than one token for $\mathrm{C}$; how much more depends on the treatment, below. This 'multiplier' can be interpreted as the effectiveness of the care worker. Since care workers have formal training, they can provide 'better' care than the care manager (or family member). How effective, or efficient, a worker is can be impacted positively by the quality of training they receive and negatively by red tape and heavy caseloads. An alternate (or complementary) interpretation would be that the care worker has a lower opportunity cost of time than the care manager/family member. For our purpose, either interpretation is valid. The case where the family member is better trained and has a lower opportunity cost of time is not considered here.

Unfortunately for A, sending tokens to B is risky in terms of providing care. Just as family members cannot perfectly monitor and contract with the workers that provide care for their family members, A cannot force B to provide a high level of care for C. In this way, the 
relationship (between the care manager and skilled worker) is one requiring trust: If the worker is hired, then the manager must trust them to 'do the right thing' and provide care for the needy recipient. The worker has an incentive to shirk and thus fail to provide adequate care. Even in our setting, where A receives perfect information about B's previous-round behavior, the inability to write a contract contingent on effort makes this a trust relationship.

The total level, or quality, of care that $\mathrm{C}$ receives is equal to the number of tokens they receive directly from A plus the multiplied number of tokens given by B. Thus, earnings for a single round can be summarized as follows:

(1) Earnings $_{A}=E+$ Budget - Send $_{A \text { to } B}-$ Send $_{A \text { to } C}+0.25\left(\right.$ Earnings $\left._{C}\right)$

(2) Earnings $_{B}=E+\operatorname{Send}_{A \text { to } B}-\operatorname{Send}_{B}$ to $C$

(3) Earnings $_{C}=\operatorname{Send}_{A \text { to } C}+$ Multiplier $\times \operatorname{Send}_{B}$ to $C$

where $\mathrm{E}$ is the endowment. Notice that the Nash equilibrium in this game, assuming payoffmaximizing players, is for A to keep everything, B to keep everything, and $\mathrm{C}$ to receive zero care. Resulting earnings are (10+ Budget) for A, 10 for B, and zero for C. However, the efficient outcome (due to the multiplier) is for A to send everything to B and for B to send everything to C. For example, in the case of a zero care budget and a multiplier of 3, B would earn zero and C would earn $20 * 3=60$ tokens, with A earning .25 times C's earnings $=15$. This would result in a highly skewed distribution of resources, and is unlikely to occur. It is possible to get an equaldivision outcome, but this requires the participation of both an $\mathrm{A}$ and $\mathrm{B}$ who both have a preference for equality (See Online Appendix Table A2 for equal-payoff combinations).

We vary two key parameters of the experimental model that mimic home care subsidies and worker training subsidies: the care budget and the multiplier. By increasing the budget available to care managers, we mimic subsidies for home care, and estimate the impact 
additional subsidies have on care outcomes. We conduct three treatments; a baseline treatment with no care budget (representing completely out-of-pocket care); a low budget treatment where A receives 2 tokens (a bonus of $20 \%$ of endowment) for the purposes of taking care of $\mathrm{C}$; and a high budget treatment where A receives 8 tokens (a bonus of $80 \%$ of endowment) for the purposes of taking care of C. ${ }^{7}$

Additional treatments vary the effectiveness of the care workers by changing their multipliers. Recall that our base model assumes that care workers are more effective at providing care than player A, due to training and institutional support. We then exogenously impact the effectiveness from this base level. These changes can be positive (like increased institutional support, better workloads, increased training, or better role models) or negative (broken equipment, poor own-health, increased workloads, and so on). We then consider a return-tobaseline to evaluate what happens when these policies and interventions end.

[Table 1]

Specifically, the game is divided into three blocks of 10 rounds each. The first block (rounds 1-10) has a multiplier for B's tokens of 3. The second block (rounds 11-20) varies the multiplier of the worker according to the treatment; the negative change to effectiveness reduces the multiplier to 2 , whereas a positive change to effectiveness increases the multiplier to 4 . The third and final block (rounds 21-30) is identical to the first block of ten rounds and reinstates the standard multiplier of three. We run all combinations of the budget and training subsidy treatments yielding a $3 \times 2$ experimental design, shown in Table 1.

\subsection{Procedure and Implementation}

A total of 207 subjects participated in sessions run between April and October 2010 and

\footnotetext{
${ }^{7}$ The instructions state, "You also receive a budget of X tokens because you are responsible for taking care of C."
} 
in Fall 2011 at the Center for Behavioral and Experimental Economic Science (CBEES) at the University of Texas at Dallas (now closed). All participation was voluntary, and individuals were recruited through the Center's online recruiting system. Experiments were programmed in z-Tree (Fischbacher 2007). Participants play 30 rounds with the same group members. This is done to reflect the stable nature of many of these relationships.

As summarized in Table 1, the care manager either had no care budget, a low care budget of 2 tokens, or a high care budget of 8 tokens. The multiplier on the number of tokens B sends to $\mathrm{C}$ was always equal to three for round 1-10 and rounds 21-30. For rounds 11-20, the multiplier could be either two or four.

Once the experiment was finished, participants completed a short socio-demographic and perceptions survey, and were paid one at a time in private. On average, participants earned $\$ 16.32$ for approximately 90 minutes. On average, Player A earned $\$ 18.15$, B earned $\$ 17.68$, and C earned \$13.14. Sample screen shots are available in Online Appendix C.

\section{Results}

We now turn to the analysis of each type of players' behavior, as well as the impact of the multiplier and the budget. The first-mover in this game is A, the care manager. Thus, we will begin by examining the choices that they make, both in aggregate as well as factors which impact individual decision making. After that we examine the choices of B, and finally, the care outcomes for $\mathrm{C}$.

\subsection{Principal: Care Manager Behavior}

Recall that A must decide how many tokens to keep for herself, how many to send to B and how many to send to C. Two key metrics are of interest in this setting. The first is the absolute amount that each player receives: This will allow us to examine the level, or quality of 
care that $\mathrm{C}$ receives. The second is how much each receives, relative to the total available. This allows us to examine the relative gains that come from changing multipliers or from the additional budget. In other words, it provides a clearer picture as to whether these policy changes result increase the level of care provided relative to the resources available.

Figure 2 provides an aggregate summary of A's choices for each treatment, pooled over all rounds. The first panel shows the actual division of tokens, whereas the second panel displays the distribution of tokens as a percent of the total available to A. Within each panel, results are displayed for each of the three budgets $(0,2$, and 8$)$ as well as for both of the multiplier schemes $(3,2,3$ and 3, 4, 3). The bars show all three of A's decisions simultaneously: The bottom part of the bar, in dark grey, represents the amount A keeps for herself; the middle portion of the bar, in light grey, represents the amount A sends to B; and the top portion of the bar, in medium grey, represents the amount A sends directly to $\mathrm{C}$.

[Figure 2]

This figure highlights a few key points regarding A's behavior. Note that, contrary to the Nash equilibrium prediction, A players send, on average, positive amounts to both B and C. Also note that, regardless of budget or treatment, A keeps between $60 \%$ and $80 \%$ of the total amount available to them. A additionally sends a significant portion to B under all conditions as well as a smaller but non-negligible amount directly to $\mathrm{C}$.

To examine the care managers' use of skilled workers, we estimate the following random effects GLS panel regression,

(4) $\quad A_{-} B_{i t}=\alpha+\beta$ Treatments $_{i t}+$ Period $_{t}+\gamma X+\varepsilon_{i t}$ where $A_{-} B_{i t}$ is subject $i$ 's transfer to the worker (B) at period $t$, dummy variables are implemented which equal one if the subject is in treatment in question; $X$ is a set of individual 
characteristics; and $\varepsilon$ is the error term. The budget treatments use a dummy to signify whether subject $i$ was in the low or high budget treatments (the base case is no budget), and the effectiveness treatments equal one if the multiplier has changed to two (M2) or four (M4) for subject $i$ in period $t$. The variable $A_{-} B_{i t}$ is the actual amount sent from $A$ to $B$ in period $t$. We also present results on the amount sent as a percentage of the total available to them (their endowment plus any care budget) in the second pair on columns. For both the actual and relative amount sent, the first column presents the results without $B$ 's lagged contribution to $C$, while the second includes it. Table 2 reports marginal effects, with standard deviations in parentheses. Online Appendix Table B1 describes all of the variables. ${ }^{8}$

[Table 2]

Turning to the first treatment, the budget subsidy, we see that a low budget subsidy (of two tokens) has no significant impact on A's usage of care workers (trust toward, or transfers to B) whereas a high budget subsidy (of 8 tokens) positively and significantly impacts care worker usage, but only by an additional 1.88 tokens. These marginal effects are also significantly different from each other $\left(\chi^{2}(1)=10.42, p=0.001\right)$. The increase in tokens does not result in a statistically significant increase in the amount sent as a percentage of the total available to A.

For the second treatment, the changes in care worker effectiveness, we see that care managers are sensitive to the positive shocks to worker effectiveness, with A increasing usage of care workers by 0.297 when the multiplier is four instead of three. A significantly responds to increases in care worker effectiveness by increasing their expenditure on care, but they do not significantly reduce expenditures when care worker effectiveness is reduced. These marginal

\footnotetext{
${ }^{8}$ Appendix Table B2 includes $A_{-} C_{i t}$ only to account for the reduced amount available to potentially send to B. While these decisions are made jointly, a Hausman specification test on model 1 confirms that the coefficient estimates for the random effects model are consistent (Prob $>\chi^{2}=0.87$ ).
} 
effects are significantly different from each other $\left(\chi^{2}(1)=6.95, \mathrm{p}=0.01\right)$. Further, and contrary to our results for the budget subsidy, these expenditure increases are statistically significant when examining expenditures as a percentage of resources available.

The second model incorporates the group's history: specifically, B's transfer to C in the previous period (or past trustworthiness). These lagged transfers are, by construction, endogenous. Thus, caution is warranted in their interpretation. Results suggest that care managers send more to trustworthy care workers, but not enough to make it worthwhile for B to strategically send more to $\mathrm{C}$ as a result. That is, B's generosity is not sufficiently rewarded to make it "pay" as a strategy. We see a slight decay in transfers over time. We additionally include controls for gender, age, ethnicity, and work status. We find no gender effect, though other signs go the expected direction.

These results suggest that any policy aimed at increasing care worker effectiveness will also need to clearly communicate the gains in effectiveness to the care managers and public at large in order to fully realize the behavioral impacts of the policy.

Of course, usage of care workers by care managers is one potential avenue to provide care for C: Care managers can also give directly to the recipients in response to the treatment. To gauge the effects of the treatments on direct giving, we estimate the following random effects GLS model, shown in Table 3:

$$
A_{-} C_{i t}=\alpha+\beta \text { Treatments }_{i t}+\operatorname{\theta Period}_{t}+\gamma X+\varepsilon_{i t} \text {, }
$$

which is identical to the specification above, but with A's transfer to C (directly) in period $t$ as the dependent variable. ${ }^{9}$ The first column uses the amount sent as the dependent variable while the second uses the amount sent as a percentage of the total available to A.

\footnotetext{
${ }^{9}$ Online Appendix Table B3 provides estimates including $A_{-} B_{i t}$ and lagged variables. A Hausman specification test indicates that $A_{-} B_{i t}$ is not causing the estimates to be inconsistent ( $\operatorname{Prob}>\chi^{2}=0.81$ ). Key results are unchanged.
} 
[Table 3]

Care managers give directly to care recipients, but subsidies only impact the absolute level of care when they are large (giving increases by 1.297 tokens in the first model). ${ }^{10}$ Further, subsidies do not increase care as a percentage of the total available. This level of informal care that $\mathrm{A}$ is providing to $\mathrm{C}$ is not impacted by the effectiveness of the care worker. Thus, the effectiveness treatments do not create a substitution effect in our data: Changes in care worker effectiveness impact the level of formal care provided but not the level of informal care.

Based on this evidence and in our abstract setting, the A's act, on aggregate, in a manner most consistent with warm glow giving (Andreoni 1990). Our care managers provide directly to $\mathrm{C}$ (providing the care themselves) and through B (caring about total provision). However, this masks considerable heterogeneity at the individual level, as highlighted in Appendix Figure B2. In the next section we examine the effects of the treatments on care worker behavior.

A's Motives: A's choose to give directly to C, which is not consistent with payoff maximization, efficiency maximization, inequality aversion, target earnings, reciprocity, or mental accounting (See Online Appendix A). Player A does not substantially increase giving as the budget increases enough to be consistent with either efficiency maximization or inequality aversion. Further, A sends more to B when the multipliers are higher, which contradicts target earnings, reciprocity, and mental accounting. Thus, A's behavior is most consistent with warm glow preferences, where individuals care about both total provision and their own level of provision.

\subsection{Agent: Care Worker Behavior}

We now turn to a discussion of the decisions made by subjects in the role of $\mathrm{B}$, the care

\footnotetext{
${ }^{10}$ The marginal effects are significantly different from each other, $\chi^{2}(1)=4.42, p=0.04$ in model 1 .
} 
worker. The first panel in Figure 3 shows B's average allocation of tokens, across all rounds, by budget and treatment. Remember that $\mathrm{A}$ has a different amount available under the various subsidy schemes, and that the total amount B has available depends both on his 10-token endowment and the amount sent by A. For each budget-treatment pair, the graph pools all rounds. The height of the bar indicates the mean number of tokens available to $\mathrm{B}$. The black portion of the bar represents the amount B players keep for themselves while the white portion indicates the number of tokens transferred to $\mathrm{C}$ (before the multiplier is applied). The second panel provides this same information, except that it shows the allocations made by B as a percent of the total tokens available to them.

\section{[Figure 3]}

In all cases, note that the care worker is sending a positive amount to $\mathrm{C}$, but in most cases B is sending less than $20 \%$ of the total available to them, on average. In addition, while transfers from A increase the amount sent to $\mathrm{C}$, the care workers are keeping some of the transfer from A for themselves: the pass-through is not one-for-one. We will now turn to an analysis of B's decisions.

To examine behavior of care workers as a response to the treatment, we estimate the following random effects GLS panel regression, shown in Table 4:

(6) $B_{-} C_{i t}=\alpha+\beta$ Treatments $_{i t}+\delta A_{-} B_{i t}+\theta$ Period $_{t}+\varepsilon_{i t}$ where $B_{-} C_{i t}$ is subject $i$ 's transfer to the care recipient (C) at period $t$, dummy variables are implemented which equal one if the subject is in treatment in question (budget/efficiency); $A_{-} B_{i t}$ is the number of tokens sent by the care manager to the worker; and $\varepsilon$ is the error term.

[Table 4]

Similar to the specification for A's behavior, we investigate the treatments and include 
controls for demographics. The first column of Table 4 considers a linear relationship between $A \_B_{i t}$ and $B \_C_{i t}$, while the second column allows for a non-linear relationship. In the linear specification, the $\mathrm{B}$ sends 0.611 tokens to $\mathrm{C}$ for every one they receive from $\mathrm{A}$. In the non-linear relationship, for each token A sends to B, B sends 0.311 tokens. In either case, B players respond to greater trust on the part of the A players by increasing care for $\mathrm{C}$ players. Transfers to $\mathrm{C}$ are stable over time, and do not vary with gender, age, or work status.

We interpret the positive but less than one-to-one transfer as a type of reciprocity. Specifically, it appears that care workers pass through part of the transfer, and keep the rest as wages. ${ }^{11}$ We find no evidence of this fraction changing as a result of the treatments. Note that in the money-maximizing Nash equilibrium of this finite game (with payoff-maximizing players), B should keep all the tokens sent from A. This indicates that B's pro-social motivation, conditional on the trust placed in them by $\mathrm{A}$, is what is driving their behavior.

An additional potential explanation is that, strategically, $\mathrm{B}$ provides high transfers to $\mathrm{C}$ in order to receive higher transfers from A in the future, thereby increasing his own earnings. This does not appear to be the case here. First, given the estimated 'reward' of higher usage (estimated to be 0.435 per token of B's previous transfer, as shown in Table 2), this strategy would be unlikely to pay off. The question can be better investigated through last period play, when these strategic considerations are no longer present. These results are shown in Table 5. Even in this last period, B is sending 0.694 of every token received from A.

\section{[Table 5]}

$B$ 's Motives: B players do not pass their entire endowment plus the transfer from A, and

\footnotetext{
11 Appendix Figure B3 provides a sample of the individual data. Note that many player B's do not receive any transfer from A. Restricting the Table 4 analysis to those B's who receive positive transfers in period $t$ (1261 observations), we see the linear marginal effect is $0.679(\mathrm{p}=0.00)$ and for the non-linear model, the main effect is $0.255(\mathrm{p}=0.00)$ and the squared term is $0.028(\mathrm{p}=0.00)$ (results not shown).
} 
B's transfers generally are below the amount B receives from A, making their decisions inconsistent with efficiency maximization, warm glow, and mental accounting. B's transfers to C are not negatively impacted by the multiplier as implied by inequality aversion or target earnings. Thus, B's decisions are most consistent with a preference for reciprocity, where B is paying-forward the trust placed in them by A.

\subsection{Overall Quality of Care Provided}

Our final metric is to identify the effect of treatments on the quality of care received by the care recipient. In our experiment, this is measured as the number of tokens received by player C. We estimate the following random effects GLS panel regression, shown in Table 6:

(7) Earnings $_{C t}=\alpha+\beta$ Treatments $_{i t}+\theta$ Period $_{t}+\varepsilon_{i t}$ where Earnings $_{C t}$ is subject $C$ 's earnings at period $t$; and the other terms are as previously described. We first turn our attention to the effect of the budget: while we did see A increasing their contribution under the high budget treatment, we see no statistically significant impact on C's welfare from either of our care budget treatments. Indeed, the lion's share of the subsidies are being captured by player A, with a little being captured by player B's and insignificant increases to C's welfare, as shown in Figure 4.

\section{[Table 6 \& Figure 4]}

Increasing the effectiveness of care workers positively and significantly improves C's welfare in our setting. Each unit increase in the multiplier increases the level of care provided by approximately 2 . This effect can be divided up into both a direct and indirect effect of the multiplier. Of the 2 token increase, one token is directly due to higher multiplier. The indirect effect comes through the response of care managers and workers. There is no shift in care worker effort (which remains the same regardless of treatment), but there is a unilateral increase in care 
managers' use of the worker (which is also considered at the higher rate), thereby translating into higher welfare for the recipient.

Finally, we turn to an examination of the distribution of earnings. Figure 4 summarizes the impact of the budget on earnings in the baseline $(\mathrm{M}=3)$ and Increasing A's care budget to 2 increases A's earnings by 1.84 tokens, indicating that the smaller budget accrues mostly to the care manager. For the higher budget, A earns 5.81 tokens more than in the no-budget treatment. C's earnings do increase by 2.54 , but the majority of the higher budget is captured by A. Further, the difference was insignificant once we controlled for other factors, as shown in Table 6.

Figure 5 summarizes the impact of the multiplier on earnings in each of the budget treatments. For the no budget case, A's earnings increase by 1.52 tokens between the least effective $(M=2)$ and most effective $(M=4)$ cases. C's earnings increase as well, by 3.12 tokens between the least effective $(M=2)$ and most effective $(M=4)$ cases. The low budget shows a similar trend. For the high budget case we see a similar trend for B and C, but higher, stable earnings for A.

\section{[Figure 5]}

\section{Closing Discussion}

As the population ages, the demand for care workers is increasing. Families face difficult choices. Nursing homes and assisted care facilities are costly, and often are seen as unattractive options. Family members frequently decide to provide informal care for elderly family members. In this paper we create the first experimental model of key components of the care sector (a model that is potentially applicable to other settings as discussed below): trust and pay-it-forward reciprocity. We then test two policy mechanisms designed to assist families in caring for their elderly. We implement the care relationship in the lab as a trust relationship between a care 
manager and a care worker. We test the impact of subsidies to care managers and the impact of changing the effectiveness of care workers. We find that care manager behavior is most consistent with warm glow preferences while care worker behavior is most consistent with reciprocal preferences.

We find that increasing the effectiveness of care workers is far more effective at increasing the welfare of the care recipient than providing subsidies to care managers. Subsidies offset the cost of caring for a needy person, but do not significantly increase the quality of care. This result occurs for two reasons. First, small subsidies are captured by care managers. In the no budget baseline, care managers donate about 2 tokens on average to increasing the welfare of the care recipient. This level of giving is fully replaced in the low budget condition. The high budget condition (which is quite high in our experiments) has a positive but statistically insignificant impact on C's welfare, meaning that there is a nominal increase in giving, but a high proportion of the subsidy is captured by the care manager. While C's welfare is not directly improved, the family welfare is increased, and this subsidy may still be beneficial overall. This effect confirms results from empirical studies: “...the empirical literature indicates that publicly provided formal home care may crowd out informal care which results in increasing public long-term care expenditure while total care provided remains constant" (Arntz and Thomsen 2011, p. 6). Note that increased monitoring of the budget subsidy may help mitigate this problem.

Alternatively, changes to care worker effectiveness significantly impact the welfare of the needy person. Each unit increase in effectiveness (here, the multiplier) translates into an approximately 2-token increase in welfare. This is due to two main factors. First, care workers are behaviorally unresponsive to changes in their effectiveness, or to the total subsidy available. Thus they do not "work harder" to offset lower effectiveness or "work less" to absorb the 
benefits of higher effectiveness. However, care managers are responsive to the effectiveness of the care workers, and transfer more resources when workers are more effective. This yields an indirect effect of increasing the effectiveness of workers; it causes no change in effort levels, but does increase their utilization, leading to greater welfare for care recipients.

Our results show clear implications for policy makers. First, they show that providing subsidies to care managers is an ineffective method of increasing welfare (though it may increase the family's welfare). The entire subsidy is captured by the manager, and indeed, reduces prosocial motives for providing care. Second, they show that focusing on effectiveness of care workers yields increases through the utilization of care workers by care managers, which in turn yields large effects in care recipient welfare. Focusing on care worker training programs and educating care managers on the value of using care workers is an important mechanism for improving welfare.

As the first experimental study of key elements of the care market, specifically pay-itforward reciprocity, the study has significant limitations, some of which can be addressed in future studies. First, the players are in anonymous groups, in contrast to the close personal relationships often observed between care workers and their charges. Relaxing anonymity will likely increase care provision, both by the care manager and the care worker. We thus view our results as a lower bound on generosity in this setting.

Second, subjects are randomly allocated to the roles of manager, worker and target. While care managers may not choose their role, care workers select into professions involving the care of others and may lose their job for poor performance. Again, these will likely increase care over the levels we observe. We have not yet explored the effects of rewards and punishment in this context. These could either increase care, or might have the perverse effect of reducing 
pro-socially-motivated care provision.

Results are applicable to other principal-agent settings with motivated agents as well. While we focus specifically on the care sector, the experiments are neutrally framed and the desire to 'do good' also impacts quality of work in many professions where quality is not directly observable, including education, police work, and public service. Results suggest that policies aimed at increasing the effectiveness of workers, for example providing additional training and reducing red tape, may be an effective mechanism to increase the quality of work in these professions.

In addition, the three-person trust relation is applicable to any setting where a principal desires to accomplish a charitable objective, but the agent may have more selfish objectives. For example, economic development aid often must be funneled through local agents to reach needy recipients, and the donor (whether a government or non-governmental organization) must trust local individuals and institutions to distribute the aid. Often it is the case that aid is difficult to track precisely, and outcomes hard to measure. Aid then fails to reach the intended recipients or produce the anticipated benefits (Easterly 2003; Gibson et al. 2005). For example, Saltmarshe and Mehdi (2011) estimate that about one third of food aid to Afghanistan is diverted and sold in markets. The structure and composition of local institutions substantially impact the effectiveness of development, a proposition tested in field experimental research (Grose 2014 provides a review). Lab experiments using adult subjects in developing countries also explore the prevalence of embezzlement and skimming by those responsible for aid distribution (d'Exelle and Berg 2014; Di Falco, et al. 2016). The experimental game we develop here could be adapted to study policies designed to aid low-income individuals, where effective distribution requires trust in local politicians and institutions. 


\section{References}

Akerlof, George A. 1982. "Labor Contracts as a Partial Gift Exchange." Quarterly Journal of Economics 97 (4): 543-569.

Akerlof, George A. and Rachel E. Kranton. 2005. "Identity and the Economics of Organizations." Journal of Economic Perspectives 19 (1): 9-32.

—. 2011. "Identity Economics: How our Identities Shape our Work, Wages, and Well-being." Economics and Philosophy 27 (3): 331-337.

Andreoni, James. 1990. "Impure Altruism and Donations to Public Goods: A Theory of Warm-Glow Giving." Economic Journal 100 (401): 464-477.

Arntz, Melanie and Stephan L. Thomsen. 2011. "Crowding Out Informal Care? Evidence from a Field Experiment in Germany." Oxford Bulletin of Economics and Statistics 73 (3): 398-427.

Ashraf, Nava, Oriana Bandiera, and Kelsey Jack. 2014. "No Margin, No Mission? A Field Experiment on Incentives for Public Services Delivery." Journal of Public Economics. 120: 1-17

Banuri, Sheheryar and Philip Keefer. 2016. "Pro-social Motivation, Effort and the Call to Public Service." European Economic Review. 83: 139-164.

Bardsley, Nicholas. 2008. "Dictator Game Giving: Altruism Or Artefact?" Experimental Economics 11 (2): 122-133. Bénabou, Roland and Jean Tirole. 2003. "Intrinsic and Extrinsic Motivation." Review of Economic Studies 70 (3): 489-520.

_. 2006. "Incentives and Prosocial Behavior." American Economic Review 96 (5): 1652-1678.

Ben-Ner, Avner and Louis Putterman. 2009. "Trust, Communication and Contracts: An Experiment." Journal of Economic Behavior \& Organization 70 (1): 106-121.

Berg, Joyce, John Dickhaut, and Kevin McCabe. 1995. "Trust, Reciprocity, and Social History." Games and Economic Behavior 10 (1): 122-142.

Besley, Timothy and Maitreesh Ghatak. 2005. "Competition and Incentives with Motivated Agents." American Economic Review 95 (3): 616-636.

Bigoni, Maria, Stefania Bortolotti, Marco Casari, and Diego Gambetta. 2013. "It takes two to cheat: An experiment on derived trust." European Economic Review 64: 129-146.

Bohnet, Iris, Fiona Greig, Benedikt Herrmann, and Richard Zeckhauser. 2008. "Betrayal Aversion: Evidence from Brazil, China, Oman, Switzerland, Turkey, and the United States." American Economic Review 98 (1): 294310.

Bolin, Kristian, Björn Lindgren, and Petter Lundborg. 2008. "Your Next of Kin or Your Own Career? Caring and Working among the 50+ of Europe." Journal of Health Economics 27 (3): 718-738.

Burke, Michael J., Sue Ann Sarpy, Kristin Smith-Crowe, Suzanne Chan-Serafin, Rommel O. Salvador, and Gazi Islam. 2006. "Relative Effectiveness of Worker Safety and Health Training Methods." American Journal of Public Health 96 (2): 315-324.

Camerer, Colin F. 2003. Behavioral Game Theory: Experiments in Strategic Interaction. New York, NY: Russell Sage Foundation. 
Carlson, Barbara Lepidus, Leslie Foster, Stacy B. Dale, and Randall Brown. 2007. "Effects of Cash and Counseling on Personal Care and Well-being." Health Services Research 42 (1): 467-487.

Carpenter, Jeffrey P., Stephen Burks, and Eric Verhoogen. 2005. "Comparing Students to Workers: The Effects of Social Framing on Behavior in Distribution Games." In Field Experiments in Economics (Research in Experimental Economics), Vol. 10, edited by Jeffrey P. Carpenter, Glenn W. Harrison and John A. List, 261-289: Amsterdam: Elsevier.

Carpenter, Jeffrey, Peter Hans Matthews, and John Schirm. 2010. "Tournaments and Office Politics: Evidence from a Real Effort Experiment." American Economic Review 100 (1): 504-517.

Casadesus-Masanell, Ramon. 2004. "Trust in Agency." Journal of Economics \& Management Strategy 13 (3): $375-$ 404.

Cassar, Alessandra and Mary Rigdon. 2011. "Trust and Trustworthiness in Networked Exchange." Games and Economic Behavior. 71 (2): 282-303.

Charness, Gary and Matthew Rabin. 2002. "Understanding Social Preferences with Simple Tests." Quarterly Journal of Economics 117 (3): 817-869.

Charness, Gary, Guillaume R. Frechette, and John H. Kagel. 2004. "How Robust is Laboratory Gift Exchange?" Experimental Economics 7 (2): 189-205.

Cherry, Todd L., Peter Frykblom, and Jason F. Shogren. 2002. "Hardnose the Dictator." American Economic Review 92 (4): 1218-1221.

Croson, Rachel and Nancy Buchan. 1999. "Gender and Culture: International Experimental Evidence from Trust Games." American Economic Review 89 (2): 386-391.

Deci, Edward L., Richard Koestner, and Richard M. Ryan. 1999. "A Meta-Analytic Review of Experiments Examining the Effects of Extrinsic Rewards on Intrinsic Motivation." Psychological Bulletin 125 (6): 627668.

d'Exelle, Ben, and Marrit Berg. "Aid Distribution and Cooperation in Unequal Communities." Review of Income and Wealth 60, no. 1 (2014): 114-132.

Di Falco, Salvatore, Brice Magdalou, David Masclet, Marie Claire Villeval and Marc Willinger, "Embezzlement, transparency and the organization of the transfer chain: An experiment in Tanzania." Unpublished manuscript, 2016.

Dubois, Carl-Ardy, Martin McKee and Berns Rechel. 2006. "Introduction: Critical Challenges Facing the Health Care Workforce in Europe." In The Health Care Workforce in Europe: Learning from Experience. Bernd Rechel, Carl-Ardy Dubois and Martin McKee Eds. World Health Organization on behalf of The European Observatory on Health Systems and Policies. pp. 1-18.

Dufwenberg, Martin and Georg Kirchsteiger. 2004. "A Theory of Sequential Reciprocity.” Games and Economic Behavior. 47 (2): 268-298.

Dur, Robert, and Robin Zoutenbier. 2015. "Intrinsic Motivations of Public Sector Employees: Evidence for Germany." German Economic Review 16(3): 342-366.

Easterly, William. 2003. "Can Foreign Aid Buy Growth?" The Journal of Economic Perspectives. 17 (3): 23-48. 
Eckel, Catherine C. and Philip J. Grossman. 1996. "Altruism in Anonymous Dictator Games." Games and Economic Behavior 16 (2): 181-191.

Eckel, Catherine, Philip J. Grossman, Cathleen A. Johnson, Angela C. M. de Oliveira, Christian Rojas, and Rick Wilson. 2011. "Social Norms of Sharing in High School: Teen Giving in the Dictator Game." Journal of Economic Behavior \& Organization 80 (3): 603-612.

Engelmann, Dirk and Martin Strobel. 2004. "Inequality Aversion, Efficiency, and Maximin Preferences in Simple Distribution Experiments." American Economic Review 94 (4): 857-869.

England, Paula. 2005. "Emerging Theories of Care Work." Annual Review of Sociology 31 (1): 381-399.

England, Paula, Michelle Budig and Nancy Folbre. 2002. "Wages of Virtue: The Relative Pay of Care Work." Social Problems 49 (4): 455.

England, Paula and Nancy Folbre. 2003. "Contracting for Care." In Feminist Economics Today: Beyond Economic Man, edited by Marianne A. Ferber and Julie A. Nelson, 61-79: Chicago; University of Chicago Press.

Ettner, Susan L. 1996. "The Opportunity Costs of Elder Care." Journal of Human Resources 31 (1): 189-205.

Falk, Armin and Urs Fischbacher. 2006. "A Theory of Reciprocity." Games and Economic Behavior 54 (2): 293315.

Fehr, Ernst, Georg Kirchsteiger, and Arno Riedl. 1996. "Involuntary Unemployment and Non-Compensating Wage Differentials in an Experimental Labour Market." Economic Journal 106 (434): 106-121.

Fehr, Ernst and Urs Fischbacher. 2002. "Why Social Preferences Matter — the Impact of Non-Selfish Motives on Competition, Cooperation and Incentives." Economic Journal 112 (478): C1 - C33.

Fehr, Ernst, Erich Kirchler, Andreas Weichbold, and Simon Gächter. 1998. "When Social Norms Overpower Competition: Gift Exchange in Experimental Labor Markets." Journal of Labor Economics 16 (2): 324.

Fehr, Ernst and Klaus M. Schmidt. 1999. "A Theory of Fairness, Competition, and Cooperation." Quarterly Journal of Economics 114 (3): 817-868.

Felton, James. S. 1998. "Burnout as a Clinical entity - Its Importance in Health Care Workers." Occupational Medicine 48 (4): 237-250.

Fischbacher, Urs. 2007. “z-Tree: Zurich Toolbox for Ready-Made Economic Experiments.” Experimental Economics. 10: 171-178.

Folbre, N. 2008. "When a Commodity is Not Exactly a Commodity." Science 319 (5871): 1769-1770.

Folbre, Nancy, ed. 2012. For Love and Money: Care Provision in the United States. New York: Russell Sage Foundation.

Forsythe, Robert E., Joel L. Horowitz, N. E. Savin, and Martin Sefton. 1994. "Fairness in Simple Bargaining Experiments." Games and Economic Behavior 6 (3): 347-369.

Frey, Bruno S. 1993. "Does Monitoring Increase Work Effort? The Rivalry with Trust and Loyalty." Economic Inquiry 31 (4): 663-670.

Friedman, Daniel, and Shyam Sunder. 1994. Experimental methods: A primer for economists. Cambridge University Press.

Gächter, Simon, Esther Kessler, and Manfred Königstein. 2011. "The roles of incentives and voluntary cooperation 
for contractual compliance." IZA DP No. 5774.

Gershon, Robyn R.M., David Vlahov, Sarah A. Felknor, Donald Vesley, Philip. C. Johnson, George L. Delcios, and L. R. Murphy. 1995. "Compliance with Universal Precautions among Health Care Workers at Three Regional Hospitals." American Journal of Infection Control 23 (4): 225-236.

Gibson, Clark, Krister Andersson, Elinor Ostrom, and Sujai Shivakumar. 2005. "The Samaritan's Dilemma." Political Economy of Development Aid. 13(2): 105-124.

Greiner, Ben and M. Vittoria Levati. 2005. "Indirect Reciprocity in Cyclical Networks: An Experimental Study." Journal of Economic Psychology. 26 (5): 711-731.

Grose, Christian R. "Field experimental work on political institutions." 2014. Annual Review of Political Science 17 (2014): 355-370.

Heap, Shaun, P Hargreaves and Daniel John Zizzo. 2009. "The Value of Groups." American Economic Review 99 (1): 295-323.

Hoffman, Elizabeth, McCabe Kevin, Shachat Keith, and Smith Vernon. 1994. "Preferences, Property Rights, and Anonymity in Bargaining Games." Games and Economic Behavior 7 (3): 346-380.

Johnson, Noel D. and Alexandra A. Mislin. 2011. "Trust Games: A Meta-Analysis." Journal of Economic Psychology 32 (5): 865-889.

Karlan, Dean S. 2005. "Using Experimental Economics to Measure Social Capital and Predict Financial Decisions." American Economic Review 95 (5): 1688-1699.

Kodner, Dennis L. 2003. "Consumer-Directed Services: Lessons and Implications for Integrated Systems of Care." International Journal of Integrated Care 3: 1-7.

Landsbergis, Paul A. 1988. "Occupational Stress among Health Care Workers: A Test of the Job Demands-Control Model." Journal of Organizational Behavior 9 (3): 217-239.

Lankford, Mary G., Teresa R. Zembower, William E. Trick, Dona M. Hacek, Gary A. Noskin, and Lance R. Peterson. 2003. "Influence of Role Models and Hospital Design on Hand Hygiene of Health Care Workers." Emerging Infectious Diseases 9 (2): 217.

List, John A. 2007. "On the Interpretation of Giving in Dictator Games." Journal of Political Economy 115 (3): 482 493.

Nicol, Robert, Petrina M. Sweeney, Siobah McHugh and Jeremy Bagg. 2005. "Effectiveness of Health Care Worker Training on the Oral Health of Elderly Residents of Nursing Homes." Community Dentistry \& Oral Epidemiology 33 (2): 115-124.

Phillips, Barbara and Barbara Schneider. 2007. "Commonalities and Variations in the Cash and Counseling Programs Across the Three Demonstration States." Health Services Research 42 (1): 397-413.

Plott, Charles R. "Industrial organization theory and experimental economics." journal of Economic Literature 20, no. 4 (1982): 1485-1527.

Rietz, Thomas A., Roman M. Sheremeta, Timothy W. Shields, and Vernon L. Smith. 2013. "Transparency, Efficiency and the Distribution of Economic Welfare in Pass-through Investment Trust Games." Journal of 
Economic Behavior \& Organization. 94: 257-267.

Rigdon, Mary. 2009. "Trust and Reciprocity in Incentive Contracting." Journal of Economic Behavior \& Organization 70 (1): 93-105.

Saltmarshe, Douglas, and Abhilash Medhi. 2011. Local governance in Afghanistan: A view from the ground. Kabul: Afghanistan Research and Evaluation Unit.

Serra, Danila, Pieter Serneels, and Abigail Barr. 2011. "Intrinsic Motivations and the Non-Profit Health Sector: Evidence from Ethiopia." Personality \& Individual Differences 51 (3): 309-314.

Sheremeta, Roman M., and Jingjing Zhang. 2014. "Three-Player Trust Game with Insider Communication." Economic Inquiry 52 (2): 576-591.

Spillman, Brenda C, Black J. Kirsten, and Barbara A Ormond. 2013. "Beyond Cash and Counseling: An Inventory of Individual Budget-Based Community Long Term Care Programs for the Elderly. 2006." The Kaiser Commission on Medicaid and the Uninsured. http://www.kff.org/medicaid/upload/7485.pdf. Last accessed $12 / 18 / 2012$.

Thaler, Richard H. 1990. "Anomalies: Saving, Fungibility, and Mental Accounts." Journal of Economic Perspectives 4 (1): 193-205.

Yassi, A., J. E. Cooper, R. B. Tate, S. Gerlach, M. Muir, J. Trottier, and K. Massey. 2001. "A Randomized Controlled Trial to Prevent Patient Lift and Transfer Injuries of Health Care Workers." Spine 26 (16): 1739-1746.

Yassi, Annalee, Joel Kettner, Greg Hammond, Mary Cheang, and Myrna McGill. 1991. "Effectiveness and CostBenefit of an Influenza Vaccination Program for Health Care Workers." The Canadian Journal of Infectious Diseases 2 (3): 101-108. 


\section{Tables}

Table 1. Summary of Experimental Implementation

Number of Groups in each Treatment

\begin{tabular}{cccc}
\hline \hline $\begin{array}{c}\text { Multiplier } \\
\text { (first, second, third }\end{array}$ & No Budget & Low Budget & High Budget \\
block of 10 rounds) & 0 & 2 & 8 \\
\hline $3,2,3$ & 11 & 12 & 12 \\
$3,4,3$ & 11 & 11 & 12 \\
\hline \hline
\end{tabular}

Table 2. A's Transfers to B

Random Effects Panel GLS Regression

\begin{tabular}{|c|c|c|c|c|}
\hline \multirow[b]{2}{*}{ Variable } & \multicolumn{2}{|c|}{ Amount } & \multicolumn{2}{|c|}{ Percent Available } \\
\hline & No History & History & No History & History \\
\hline Low Budget (2) & $0.124(0.592)$ & $0.155(0.385)$ & $-2.682(4.779)$ & $-2.493(3.358)$ \\
\hline High Budget (8) & $1.884(0.633)^{* *}$ & $1.625(0.412)^{* * *}$ & $3.038(5.106)$ & 1.427 (3.589) \\
\hline Less Effective $(\mathrm{M}=2)$ & $-0.255(0.148)$ & $-0.218(0.136)$ & $-1.963(0.983)^{*}$ & $-1.703(0.913)$ \\
\hline More Effective $(M=4)$ & $0.297(0.150)^{*}$ & $0.337(0.137)^{*}$ & $2.663(0.997)^{* *}$ & $2.880(0.926)^{* *}$ \\
\hline Period & $-0.021(0.006)^{* * *}$ & $-0.011(0.006)^{*}$ & $-0.129(0.040)^{* * *}$ & $-0.070(0.037)$ \\
\hline $\mathrm{B}$ to $\mathrm{C}$, lagged actual & $\ldots$ & $0.435(0.021)^{* * *}$ & $\ldots$ & $2.696(0.142)^{* * *}$ \\
\hline Female & $-0.097(0.473)$ & $0.032(0.308)$ & $-0.365(3.815)$ & $0.434(2.681)$ \\
\hline Age & $0.138(0.098)$ & $0.127(0.064)^{*}$ & $1.507(0.793)$ & $1.437(0.557)^{*}$ \\
\hline White & $0.741(0.484)$ & $0.611(0.315)$ & $4.999(3.904)$ & $4.200(2.744)$ \\
\hline Working & $1.184(0.517)^{*}$ & $0.781(0.337)^{*}$ & $7.129(1.171)$ & $4.630(2.934)$ \\
\hline Constant & $-1.484(2.147)$ & $-2.036(1.399)$ & $-15.450(17.324)$ & $-18.866(12.183)$ \\
\hline $\mathrm{R}^{2}$ - within & 0.0095 & 0.1698 & 0.0109 & 0.1543 \\
\hline $\mathrm{R}^{2}$ - between & 0.2734 & 0.5895 & 0.1869 & 0.4684 \\
\hline $\mathrm{R}^{2}$ - overall & 0.1288 & 0.3518 & 0.1029 & 0.3084 \\
\hline Wald $\chi^{2}\left(\right.$ Prob $\left.>\chi^{2}\right)$ & $41.51(0.00)$ & $498.59(0.00)$ & $35.37(0.00)$ & $411.61(0.00)$ \\
\hline
\end{tabular}

${ }^{*} \mathrm{p} \leq 0.05 \quad{ }^{* *} \mathrm{p} \leq 0.01 \quad{ }^{* * *} \mathrm{p} \leq 0.001$

Notes: 2001 observations, 69 groups, 29 observations per group. Since some models include lags, the first period is omitted from the analysis. Marginal effects shown, standard errors in parentheses. Appendix Table B2 includes the (potentially endogenous) transfer from A to C. 
Table 3. A's Transfers to C

Random Effects Panel GLS Regression

\begin{tabular}{|c|c|c|}
\hline Variable & Amount & Percent Available \\
\hline Low Budget (2) & $0.171(0.582)$ & $0.323(3.786)$ \\
\hline High Budget (8) & $1.297(0.621)^{*}$ & $3.869(4.045)$ \\
\hline Less Effective ( $\mathrm{M}=2)$ & $0.090(0.095)$ & $0.990(0.643)$ \\
\hline More Effective $(\mathrm{M}=4)$ & $-0.060(0.097)$ & $-0.777(0.653)$ \\
\hline Period & $-0.013(0.004)^{* * *}$ & $-0.101(0.026)^{* * *}$ \\
\hline Female & $0.716(0.464)$ & $0.5456(3.022)$ \\
\hline Age & $0.039(0.096)$ & $0.268(0.628)$ \\
\hline White & $0.686(0.475)$ & $5.251(3.092)$ \\
\hline Working & $-0.357(0.508)$ & $-2.857(3.306)$ \\
\hline Constant & $-0.224(2.107)$ & $0.977(13.721)$ \\
\hline $\mathrm{R}^{2}$ - within & 0.0063 & 0.0107 \\
\hline $\mathrm{R}^{2}$ - between & 0.1806 & 0.1341 \\
\hline $\mathrm{R}^{2}$ - overall & 0.1180 & 0.0892 \\
\hline Wald $\chi^{2}\left(\operatorname{Prob}>\chi^{2}\right)$ & $26.03(0.00)$ & $31.54(0.00)$ \\
\hline
\end{tabular}

Notes: 2001 observations, 69 groups, 29 observations per group. Marginal effects shown, standard errors in parentheses. Since some models include lags, the first period is omitted from the analysis. Marginal effects shown, standard errors in parentheses. Appendix Table B3 includes the (potentially endogenous) transfer from A to B and B's previous transfers to C. 
Table 4. B's Transfers to C

Random Effects Panel GLS Regression

\begin{tabular}{|c|c|c|}
\hline Variable & $\begin{array}{l}\text { B's care for C } \\
\text { Linear }\end{array}$ & $\begin{array}{c}\text { B's care for C } \\
\text { Non-Linear }\end{array}$ \\
\hline Low Budget (2) & $-0.061(0.280)$ & $-0.107(0.278)$ \\
\hline High Budget (8) & $-0.438(0.288)$ & $-0.480(0.285)$ \\
\hline Less Effective $(M=2)$ & $0.171(0.111)$ & $0.107(0.109)$ \\
\hline More Effective (M=4) & $-0.109(0.113)$ & $-0.059(0.110)$ \\
\hline A's Transfer to B & $0.611(0.017)^{* * *}$ & $0.311(0.034)^{* * *}$ \\
\hline A's Transfer to B, squared & $\ldots$ & $0.025(0.002)^{* * *}$ \\
\hline Period & $-0.005(0.004)$ & $-0.009(0.004)^{*}$ \\
\hline Female & $-0.267(0.219)$ & $-0.217(0.217)$ \\
\hline Age & $0.054(0.040)$ & $0.058(0.039)$ \\
\hline White & $0.524(0.224)^{*}$ & $0.627(0.222)^{* *}$ \\
\hline Working & $-0.417(0.259)$ & $-0.454(0.257)$ \\
\hline Constant & $-0.364(0.886)$ & $-0.057(0.880)$ \\
\hline $\mathrm{R}^{2}$ - within & 0.4080 & 0.4352 \\
\hline $\mathrm{R}^{2}$ - between & 0.6610 & 0.6756 \\
\hline $\mathrm{R}^{2}$ - overall & 0.4798 & 0.5034 \\
\hline Wald $\chi^{2}\left(\right.$ Prob $\left.>\chi^{2}\right)$ & $1495.55(0.00)$ & $1662.83(0.00)$ \\
\hline
\end{tabular}

Notes: 2070 observations, 69 groups, 30 observations per group. Marginal effects shown, standard errors in parentheses. Hausman specification tests for the linear and nonlinear models are $\left(\chi^{2}=2.14\right.$, Prob $\left.>\chi^{2}=0.71\right)$ and $\left(\chi^{2}=1.15\right.$, Prob $\left.>\chi^{2}=0.95\right)$ respectively. 
Table 5. B's Care for C in Period 30, OLS Regression

\begin{tabular}{lll}
\hline Variable & \multicolumn{1}{c}{$(1)$} & \multicolumn{1}{c}{$(2)$} \\
\hline Low Budget (2) & $-0.174(0.724)$ & $-0.510(0.670)$ \\
High Budget (8) & $-0.939(0.717)$ & $-0.1520(0.676)^{*}$ \\
A's transfer to B & $0.694(0.107)^{* * *}$ & $-0.184(0.259)$ \\
A's transfer to B, squared & $\ldots$ & $0.096(0.026)^{* * *}$ \\
Constant & $0.620(0.550)$ & $1.409(0.548)^{*}$ \\
${ }^{*} \mathrm{p} \leq 0.05$ & 0.4071 & 0.5096 \\
Notes: Marginal effects shown, standard errors in parentheses.
\end{tabular}


Table 6. C's Welfare

Random Effects Panel GLS Regression

\begin{tabular}{cl}
\hline \hline Variable & \multicolumn{1}{c}{ Impact of Treatments } \\
\hline Low Budget $(2)$ & $-0.672(1.217)$ \\
High Budget $(8)$ & $1.840(1.205)$ \\
Less Effective $(\mathrm{M}=2)$ & $-2.011(0.416)^{* * *}$ \\
More Effective $(\mathrm{M}=4)$ & $1.991(0.422)^{* * *}$ \\
Period & $-0.088(0.016)^{* * *}$ \\
Constant & $7.992(0.912)^{* * *}$ \\
$\mathrm{R}^{2}-$ within & 0.0371 \\
$\mathrm{R}^{2}-$ between & 0.0595 \\
$\mathrm{R}^{2}-$ overall & 0.0429 \\
Wald $\chi^{2}\left(\right.$ Prob $\left.>\chi^{2}\right)$ & $80.79(0.00)$ \\
\hline \hline p $\leq 0.01 \quad$ p $\leq 0.001$ &
\end{tabular}

${ }^{*} \mathrm{p} \leq 0.05$

${ }^{* *} \mathrm{p} \leq 0.01$

bservations per group. Marginal effects shown, Notes: 2070 observations, 69
standard errors in parentheses. 
Figures

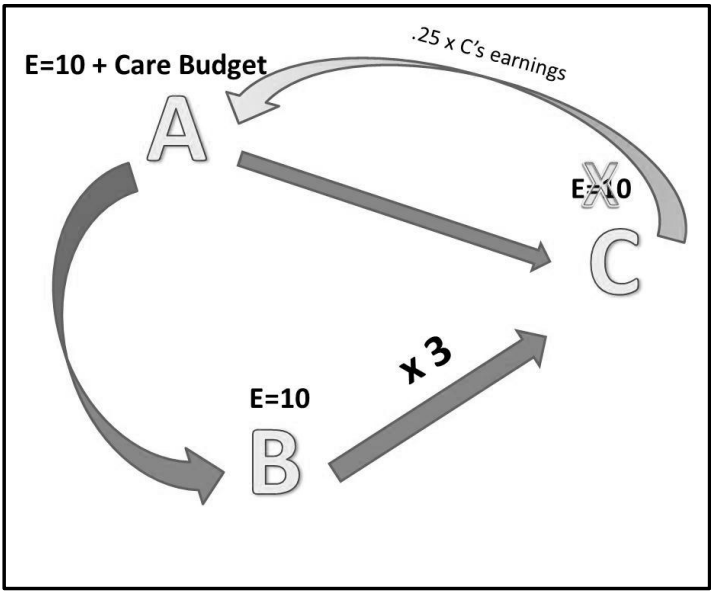

Figure 1. Care Game Design

Total Tokens

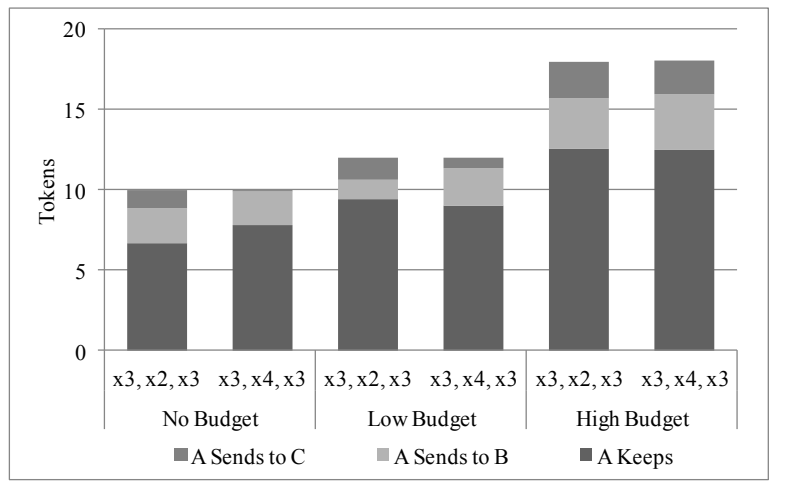

Percent of Tokens

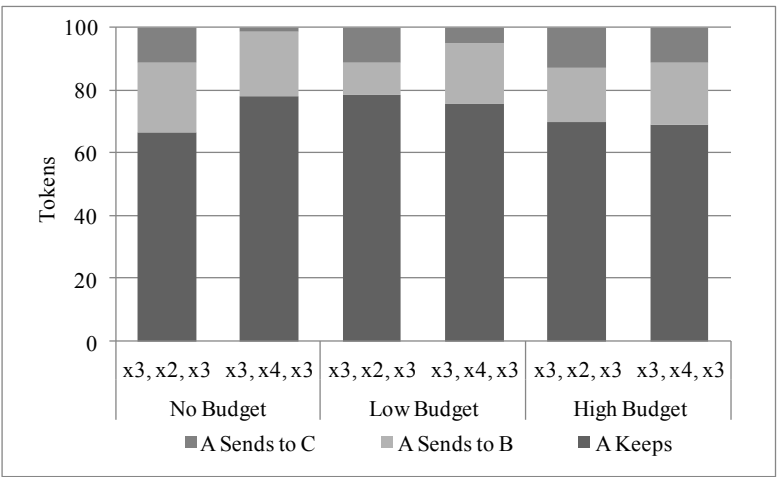

Figure 2. Average Token Allocations by Player A, by Treatment

Note: Pooled over all player A's and rounds 


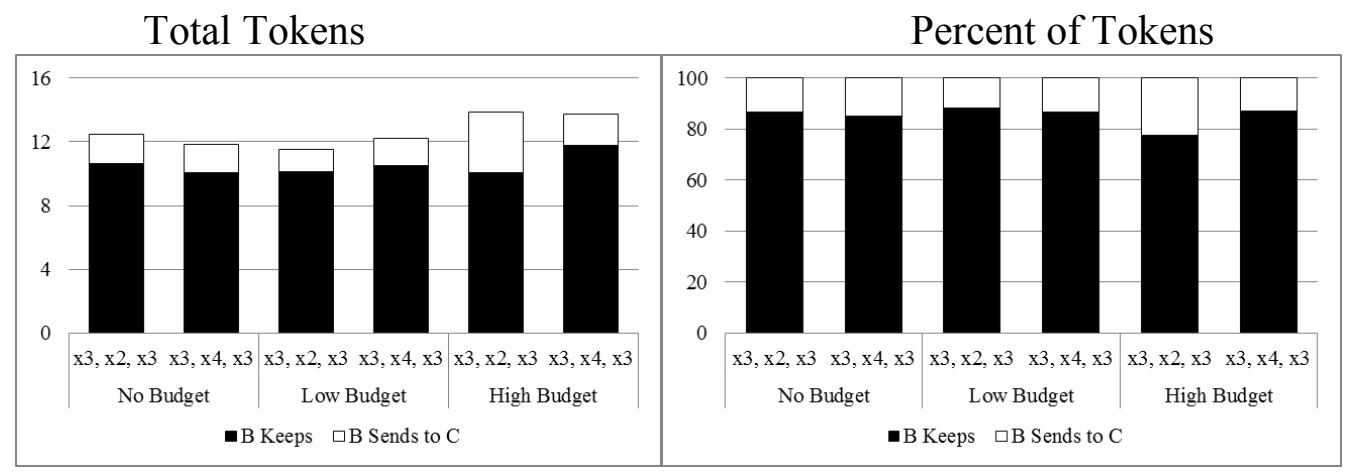

Figure 3. Average Token Allocations by Player B, by Block and Treatment

Note: Pooled over all player A's and rounds

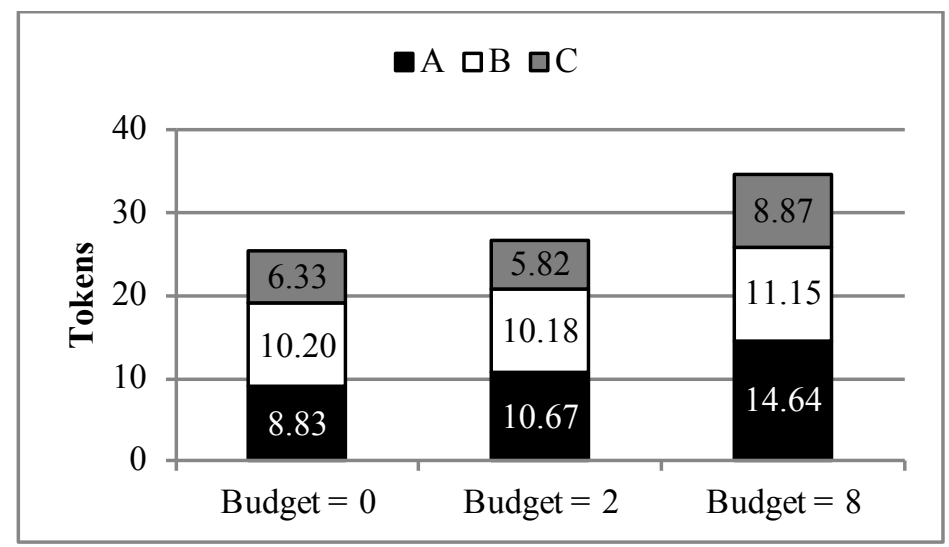

Figure 4. Impact of Budget on Average Welfare/Earnings

Pooling across all rounds where $\mathrm{M}-3$, in tokens

Note: Mean Earnings are for the decisions, not including payments for correct expectations. 
Panel A. No Budget

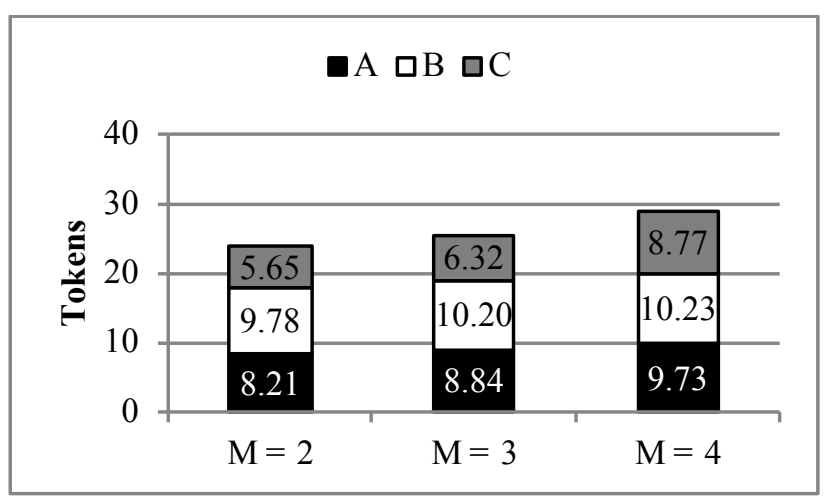

Panel B. Budget $=2$

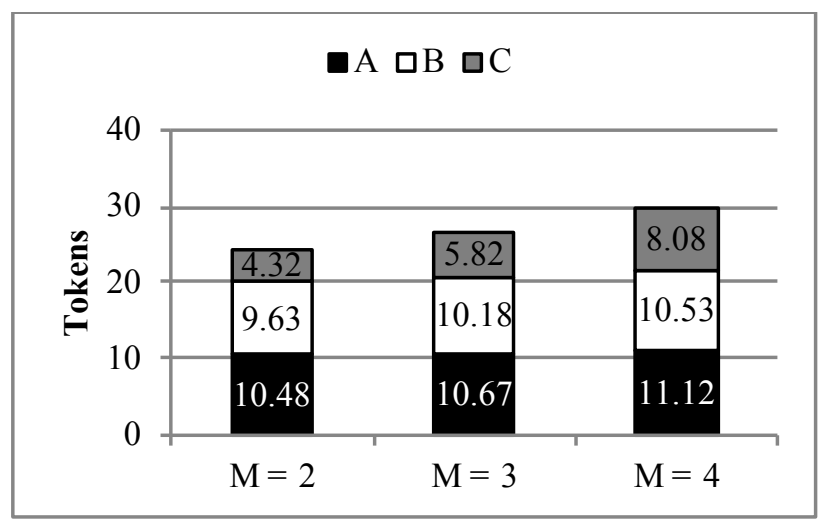

Panel C. Budget $=8$

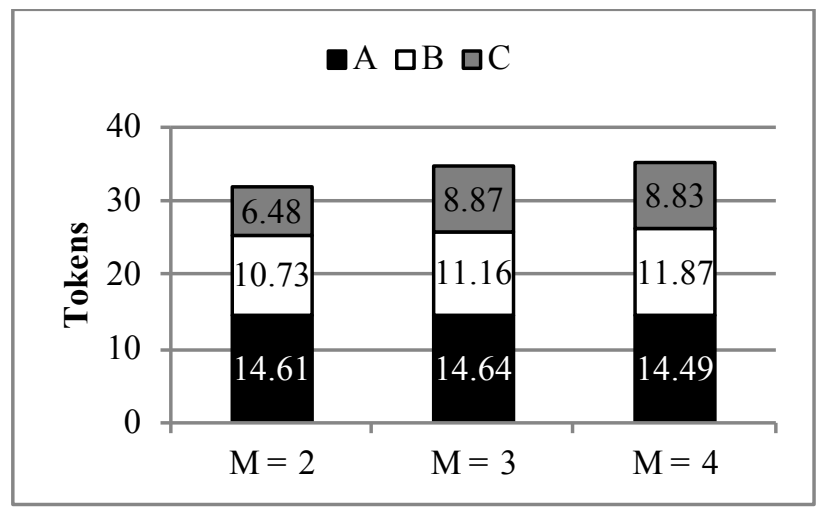

Figure 5. Impact of Multiplier on Average Welfare/Earnings

Pooling Across all Rounds, by Budget Treatment, in Tokens

Note: Mean earnings are for the decisions, not including bonuses payments for correct expectations. 


\section{Online Appendices \\ Online Appendix A - Motives and Hypotheses}

The impact of the policy changes on the behavior of subjects will depend on agent's motives. Policy impact is further complicated by the fact that subjects interact over a number of rounds, so their behavior is interdependent. Thus the response to changes in the budget or multiplier will depend on a subject's motive, whether it be maximizing own payoffs or pursuing some other goal, as well as his responses to the actions of the other players. This section sketches predicted effects for several possible motives on the part of Players A and B, assuming that they share a common motive. Table A1 provides a summary of predictions based on these motives.

[Table A1]

Payoff-maximization. Most straightforwardly, consider the benchmark case where all agents maximize their own earnings. The naïve payoff-maximizing strategy is for both players A and B to keep their initial endowments and send nothing to Player C. For a payoff-maximizing $\mathrm{B}$, this is true even if Player A were known to respond positively to B's generosity to C by sending B additional amounts, as long as the increase in the transfer from $A$ is less than one-forone.

For a payoff-maximizing A, there is only one case where they are indifferent between keeping everything and sending everything to B. If the multiplier is four and B reveals himself to be a type of player that passes everything they receive on to C, then A's are indifferent between keeping money and sending it through B. However, if B is a profit-maximizing agent, or places a positive value on his own profit above the $\$ 10$ endowment, this will not occur. Further, if both agents are payoff maximizing there will not be any response to either policy.

Efficiency: A second motive, though unlikely in this case, that Players A and B may care solely about efficiency (e.g., Charness and Rabin 2002), which would lead them to transfer both 
endowments (via Player B) to Player C, since the efficiency-enhancing “multiplier” operates between $\mathrm{B}$ and $\mathrm{C}$. In this case an increase in the care budget will be fully transferred to $\mathrm{C}$ through $\mathrm{B}$, and any increase in the productivity of $\mathrm{B}$ will accrue to Player $\mathrm{C}$. This pattern of behavior will not be impacted by changes in the multiplier, since it is always more socially efficient to send everything to $\mathrm{C}$ through $\mathrm{B}$.

Social preferences: Besides their own earnings and overall earnings for the group, subjects may exhibit social preferences by making transfers that enhance C's wellbeing (as shown in the "real charity" experiments of Eckel and Grossman 1996, and many others). The game was not designed to distinguish between different theories of social preferences, and we make only rudimentary attempts to do so here (however, see Engelmann and Strobel 2004). Nevertheless, the possibility that social preferences play a role is strong. Fairness or inequalityaversion (Fehr and Schmidt 1999) suggest that subjects equalize earnings. With the parameters in our experiment, this is always possible (see Table A2 for equal-payoff combinations). In this case, Player A would send part of her endowment to Player B who would then design a transfer to equalize earnings. If players $\mathrm{A}$ and $\mathrm{B}$ pursue this objective, they would respond to a budget increase by transferring more to C. A larger multiplier would reduce transfers by A to B and B to C.

Players A and B may care about the earnings of Player C, but not to the extent of full equality. One possibility is that Player A and/or Player B might have a fixed target earnings level for Player C. If this is the case, as long as the target is within reach (under the setting with a zero care budget and multiplier of two), any increase in the care budget would accrue only to Player A, leaving the payoffs of $\mathrm{B}$ and $\mathrm{C}$ unchanged. A change in the multiplier, assuming $\mathrm{B}$ cooperates, can increase the earnings of all players. For example, suppose the target is $\mathrm{C}^{*}$ tokens. 
Then A would likely send an amount to B that reflects the multiplier - with less sent for higher multipliers. B would then send an amount to C that implements the target amount. Table 2 shows the amounts given that $\mathrm{A}$ and $\mathrm{B}$ have the same target $\mathrm{C}^{*}$ and are equally splitting the cost. For this preference, any additional care budget would then likely be captured by Player A.

Warm glow (Andreoni 1990) could act as a motive for transferring resources to player C, either on the part of A or B. Warm glow could be inferred as a motive if A is observed transferring resources directly to $\mathrm{C}$, or if $\mathrm{B}$ transfers resources to $\mathrm{C}$ without an initial transfer from A to B. If A has warm glow preferences, she will care both about the total welfare of C and her own provision. She will thus transfer to C directly, even in the presence of transfers from B. Given that C's care is a normal good, an increase in the budget could increase transfers from A to $\mathrm{B}$ and $\mathrm{B}$ to $\mathrm{C}$, or from $\mathrm{A}$ directly to $\mathrm{C}$.

Another possible motivation is reciprocity (e.g., Dufwenberg and Kirchsteiger 2004; Falk and Fischbacher 2006). Player B knows that A benefits from his actions in two ways: First, B knows that $\mathrm{A}$ has been given the responsibility to provide for $\mathrm{C}$, so transfers from $\mathrm{B}$ to $\mathrm{C}$ aid $\mathrm{A}$ in caring for C; second, there is a mechanical increase in A's payoff as a result of B's transfers to C. Thus, B might treat a transfer from A as "trust" and reciprocate that trust by helping C. A reciprocal B will respond positively to the amount A sends.

Mental accounting: A final possibility is that A exhibits 'mental accounting' (e.g., Thaler 1990) with respect to the care budget, and think of it as "belonging to" player C. In this case any explicit care budget would lead to the full budget being transferred to C (via B). C's earnings would depend directly on the multiplier and budget, with Players A and B earning the initial endowment of 10. Therefore, both A and B's behavior does not change in response to the multiplier, they simply pass on what they receive. 
Table A1. Summary of Possible Motivations

\begin{tabular}{|c|c|c|c|c|}
\hline $\begin{array}{c}\text { Motive } \\
\text { (for both players) }\end{array}$ & Transfer & $\begin{array}{c}\text { Baseline } \\
(\text { Multiplier }=3 ; \\
\text { Budget }=0)\end{array}$ & $\begin{array}{l}\text { Increase Multiplier } \\
\text { to } 4\end{array}$ & $\begin{array}{c}\text { Increase Budget } \\
\text { by X }\end{array}$ \\
\hline \multirow[t]{3}{*}{ Payoff Maximizer } & A_B & 0 & 0 & 0 \\
\hline & A_C & 0 & 0 & 0 \\
\hline & $\mathrm{B}$ & 0 & 0 & 0 \\
\hline \multirow[t]{3}{*}{ Efficiency Maximizer } & A_B & Endowment & Endowment & Endowment $+\mathrm{X}$ \\
\hline & A_C & 0 & 0 & 0 \\
\hline & $\mathrm{B} \_\mathrm{C}$ & Endowment + A_B & Endowment + A B & Endowment $+\mathrm{A} \mathrm{B}^{3}$ \\
\hline \multirow[t]{3}{*}{ Inequality Aversion $^{1}$} & A_B & 2.80 & 2.50 & 4.08 \\
\hline & A_C & 0 & 0 & 0 \\
\hline & $\mathrm{B} \_\mathrm{C}$ & 3.20 & 2.50 & 3.52 \\
\hline \multirow{3}{*}{$\begin{array}{l}\text { Target earnings for } C \\
\quad\left(=C^{*} \leq \mathrm{m}^{*} 20\right)^{2}\end{array}$} & A_B & $\mathrm{C}^{*} / 6$ & $\mathrm{C}^{*} / 8$ & $\mathrm{C}^{*} / 6$ \\
\hline & $\mathrm{A}_{-}^{-} \mathrm{C}$ & 0 & 0 & 0 \\
\hline & B_C & $\mathrm{C}^{* / 3}$ & $\mathrm{C}^{*} / 4$ & $\mathrm{C} * / 3$ \\
\hline \multirow[t]{3}{*}{ Warm glow } & A_B & $>0$ & $?$ & Increase \\
\hline & A_C & $\geq 0$ & $?$ & May increase \\
\hline & $\mathrm{B} \_\mathrm{C}$ & $\geq$ A_B & $?$ & Increase \\
\hline \multirow[t]{3}{*}{ Reciprocity } & A_B & $>0$ if $\mathrm{B} \_\mathrm{C}$ in previous round & unchanged & unchanged \\
\hline & A_C & -0 & 0 & 0 \\
\hline & $\mathrm{B} \_\mathrm{C}$ & $>0$ if $\mathrm{A} \_\mathrm{B}>0$ & unchanged & unchanged \\
\hline \multirow[t]{3}{*}{ Mental Accounting } & A_B & $\geq 0$ & unchanged & $+\mathrm{X}$ \\
\hline & $\mathrm{A}_{-}^{-} \mathrm{C}$ & 0 & unchanged & unchanged \\
\hline & $\mathrm{B} \_\mathrm{C}$ & $=\mathrm{A} \_\mathrm{B}$ & unchanged & $=\mathrm{A} \_\mathrm{B}$ \\
\hline
\end{tabular}

Notation: A B B is the amount A sends to B; A_C is the amount A sends to C; B C $=$ Amount B sends to C. In the comparative statics columns the sign indicates the response of the row variable to an increase in the column variable.

${ }^{1}$ See Appendix Table A2 for earnings-equalizing transfers for all multiplier/budget combinations.

${ }^{2}$ For this cell we assume that $\mathrm{A}$ and $\mathrm{B}$ share the full cost of $\mathrm{C}^{*}, \mathrm{C}$ 's target earnings.

${ }^{3} \mathrm{~A} \_\mathrm{B}$ at the higher-budget level (including $\mathrm{X}$ ). 
Table A2. Equal Payoff Allocations

\begin{tabular}{ccccc}
\hline \hline Budget & Multiplier & A_B. & B_C & Earnings $(\mathrm{A}=\mathrm{B}=\mathrm{C})$ \\
\hline 0 & 2 & 3.33 & 4.44 & 8.89 \\
0 & 3 & 2.80 & 3.20 & 9.60 \\
0 & 4 & 2.50 & 2.50 & 10.00 \\
2 & 2 & 4.67 & 4.89 & 9.78 \\
2 & 3 & 4.08 & 3.52 & 10.56 \\
2 & 4 & 3.75 & 2.75 & 11.00 \\
8 & 2 & 8.67 & 6.22 & 12.44 \\
8 & 3 & 7.92 & 4.48 & 13.44 \\
8 & 4 & 7.50 & 3.50 & 14.00 \\
\hline \hline
\end{tabular}


Online Appendix B - Supplementary Tables and Figures

\section{Supplementary instructions}

Diagram of decisions in rounds $1-10$

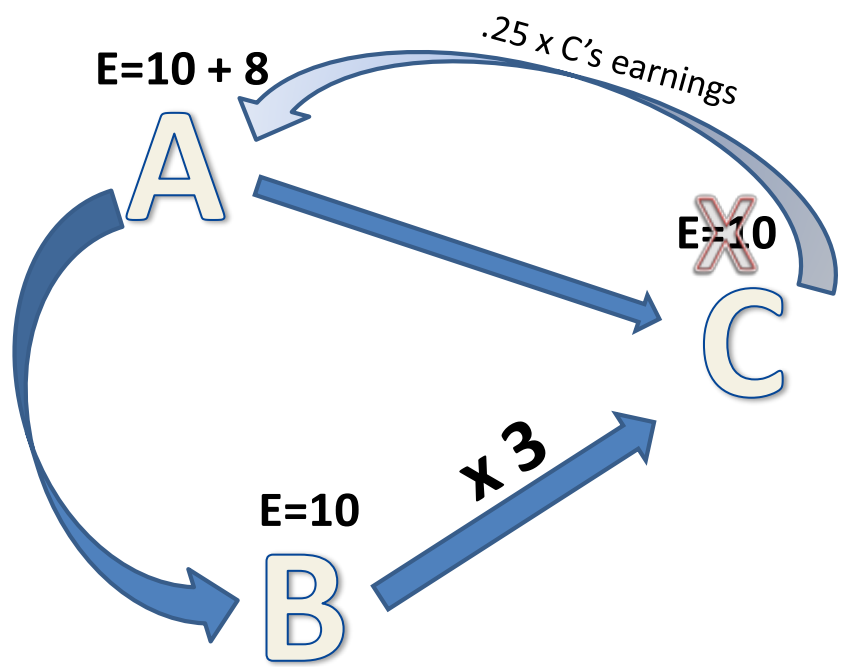

Summary of instructions:

$A, B$, and $C$ start with $E=10$. C loses $E, A$ gets 8 to care for $C$.

Decisions proceed in this order:

1. A decides how much to send to $C$ directly, and how much to send to $B$.

2. B decides now much to send to $C$. Any tokens sent are multiplied by 3 on the way.

3. C. receives tokens from $A$ and $B(\times 3)$.

4. A receives an extra payment based on C's earnings $(.25 \mathrm{x}$ C's earnings)

Figure B1. Summary Instructions 

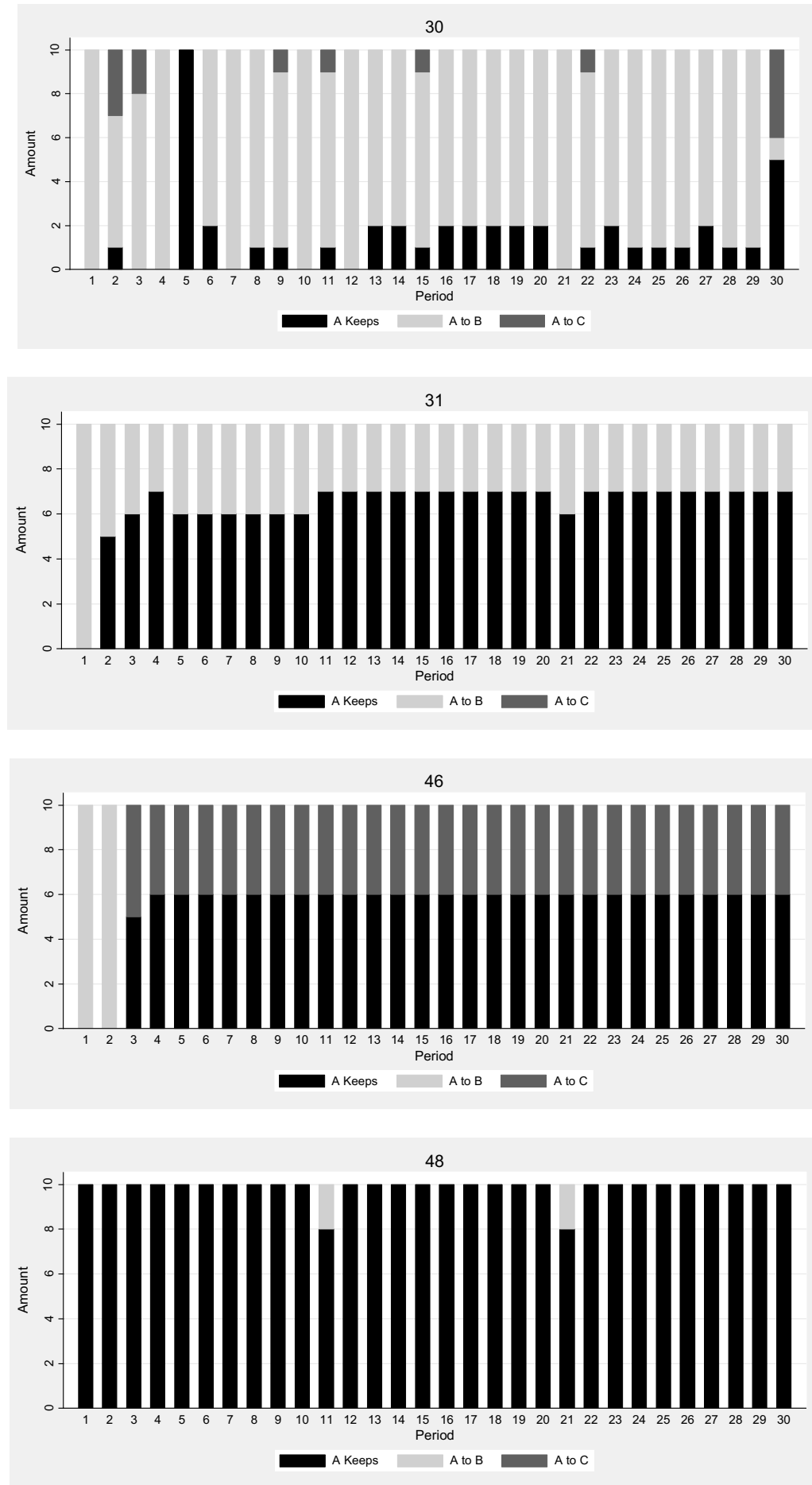

Figure B2. Sample A Behavior

Notes: No budget, all multiplier schemes 

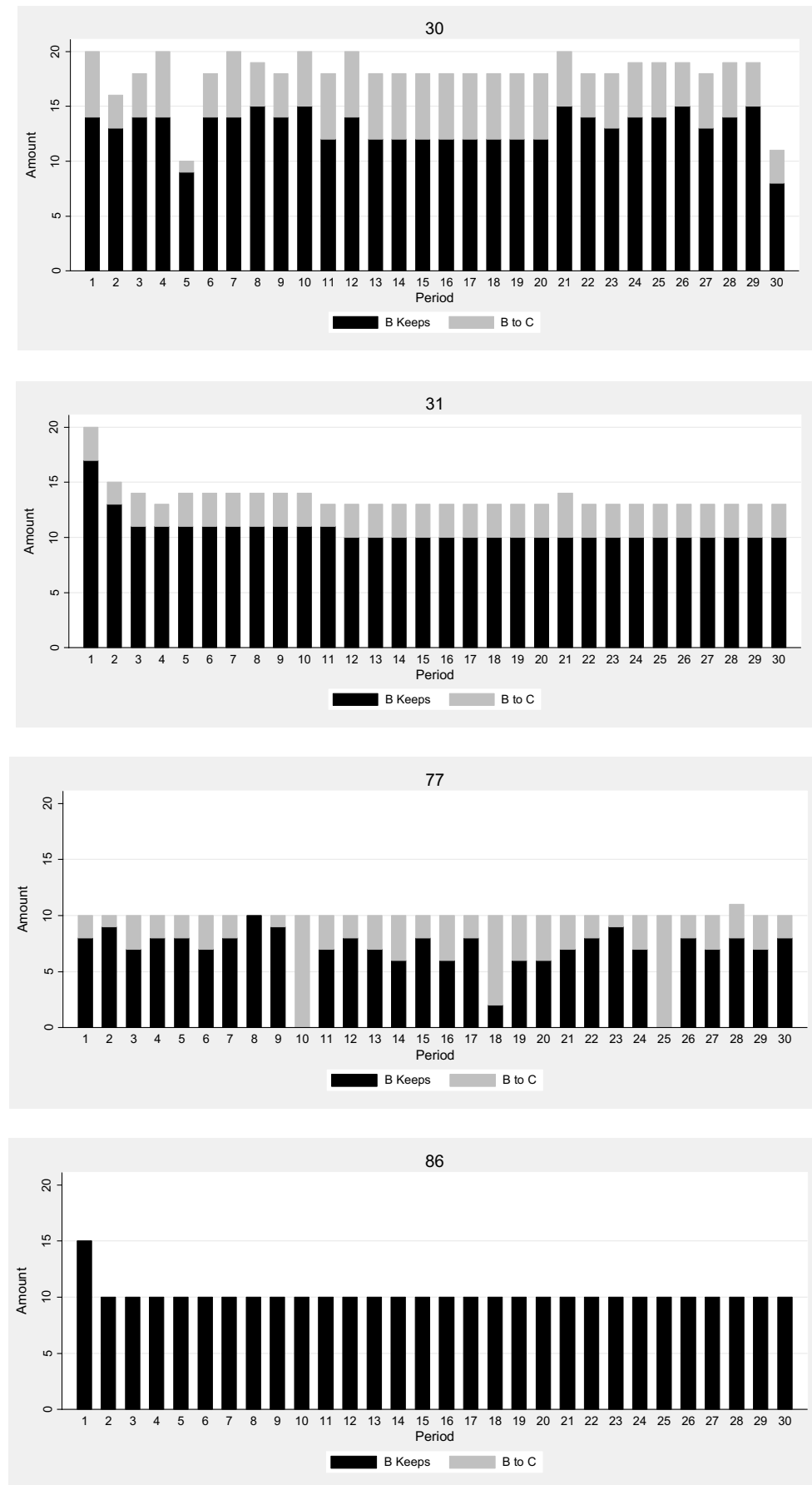

Figure B3. Sample B Behavior

Notes: Budget depends on A, all multiplier schemes 
Table B1. Variable Descriptions and Summary Statistics

\begin{tabular}{|c|c|c|c|c|c|c|}
\hline Variable & Mean & Std. Dev. & Min & Max & $\mathrm{N}$ & Description \\
\hline A's Transfer to B & 2.43 & 3.03 & 0 & 18 & 2070 & Number of tokens A sends to B \\
\hline A's Transfer to C & 1.30 & 3.37 & 0 & 18 & 2070 & Number of tokens A sends to $C$ \\
\hline B's Transfer to C & 1.91 & 2.60 & 0 & 28 & 2070 & Number of tokens B sends to $C$ \\
\hline Low Budget & 0.33 & 0.47 & 0 & 1 & 6210 & $\begin{array}{l}\mathrm{DV}=1 \text { if the care budget }=2, \\
0 \text { otherwise }\end{array}$ \\
\hline High Budget & 0.35 & 0.48 & 0 & 1 & 6210 & $\begin{array}{l}\mathrm{DV}=1 \text { if the care budget }=8, \\
0 \text { otherwise }\end{array}$ \\
\hline Less Effective & 0.17 & 0.37 & 0 & 1 & 6210 & $\begin{array}{l}\mathrm{DV}=1 \text { if the multiplier }=2,0 \\
\text { otherwise }\end{array}$ \\
\hline More Effective & 0.16 & 0.37 & 0 & 1 & 6210 & $\begin{array}{l}\mathrm{DV}=1 \text { if the multiplier }=4,0 \\
\text { otherwise }\end{array}$ \\
\hline Period & 15.5 & 8.66 & 1 & 30 & 6210 & Decision Period \\
\hline Female & 0.49 & 0.50 & 0 & 1 & 207 & $\mathrm{DV}=1$ if Female, 0 otherwise \\
\hline Age & 20.21 & 2.52 & 17 & 35 & 207 & Age, in years \\
\hline White & 0.36 & 0.48 & 0 & 1 & 207 & $\mathrm{DV}=1$ if white, 0 otherwise \\
\hline Working & 0.32 & 0.47 & 0 & 1 & 207 & $\mathrm{DV}=1$ if employed, 0 otherwise \\
\hline
\end{tabular}

Table B2. A's Transfers to B including A's Transfer to C Random Effects Panel GLS Regression

\begin{tabular}{|c|c|c|c|}
\hline Variable & (1) Design & (2) History & (3) Demographics \\
\hline Low Budget (2) & $-0.275(0.582)$ & $-0.125(0.366)$ & $0.196(0.388)$ \\
\hline High Budget (8) & $1.589(0.579)^{* *}$ & $1.451(0.365)^{* * *}$ & $1.952(0.416)^{* * *}$ \\
\hline Less Effective (M=2) & $-0.232(0.46)$ & $-0.196(0.134)$ & $-0.188(0.134)$ \\
\hline More Effective $(M=4)$ & $0.282(0.148)^{*}$ & $0.321(0.136)^{*}$ & $0.312(0.136)^{*}$ \\
\hline A's Transfer to C & $-0.283(0.034)^{* * *}$ & $-0.240(0.030)^{* * *}$ & $-0.248(0.030)^{* * *}$ \\
\hline Period & $-0.024(0.006)^{* * *}$ & $-0.014(0.006)^{* *}$ & $-0.015(0.006)^{* *}$ \\
\hline B to $C$, lagged actual & & $0.429(0.021)^{* * *}$ & $0.424(0.021)^{* * *}$ \\
\hline Female & & & $0.206(0.310)$ \\
\hline Age & & & $0.137(0.064)^{*}$ \\
\hline White & & & $0.786(0.318)^{*}$ \\
\hline Working & & & $0.703(0.339)^{*}$ \\
\hline Constant & $2.653(0.430)^{* * *}$ & $1.594(0.284)^{* * *}$ & $-2.075(1.408)$ \\
\hline $\mathrm{R}^{2}$ - within & 0.0442 & 0.1983 & 0.1986 \\
\hline $\mathrm{R}^{2}$ - between & 0.1256 & 0.4643 & 0.5589 \\
\hline $\mathrm{R}^{2}$ - overall & 0.0804 & 0.3120 & 0.3594 \\
\hline Wald $\chi^{2}\left(\right.$ Prob $\left.>\chi^{2}\right)$ & $98.09(0.00)$ & $548.95(0.00)$ & $578.39(0.00)$ \\
\hline
\end{tabular}

Notes: This table extends Table 2, in text. 2001 observations, 69 groups, 29 observations per group: The first period is omitted in column (1) for consistency with columns (2) and (3). Marginal effects shown, standard errors in parentheses. A Hausman test on column 1 fails to reject the hypothesis that the coefficients are consistent $\left(\chi^{2}=1.28\right.$, Prob $\left.>\chi^{2}=0.87\right)$. 
Table B3. A's Transfers to C Including A's Transfers to B Random Effects GLS Regression

\begin{tabular}{llll}
\hline Variable & (1) Design & $(2)$ History & $(3)$ Demographics \\
\hline Low Budget (2) & $0.306(0.539)$ & $0.312(0.522)$ & $0.189(0.559)$ \\
High Budget $(8)$ & $1.650(0.534)^{* *}$ & $1.657(0.517)^{* * *}$ & $1.529(0.598)^{*}$ \\
Less Effective $(\mathrm{M}=2)$ & $0.058(0.094)$ & $0.059(0.094)$ & $0.060(0.094)$ \\
More Effective $(\mathrm{M}=4)$ & $-0.024(0.094)$ & $-0.020(0.095)$ & $-0.020(0.094)$ \\
A's Transfer to B & $-0.120(0.014)^{* * *}$ & $-0.130(0.016)^{* * *}$ & $-0.131(0.016)^{* * *}$ \\
Period & $-0.015(0.004)$ & $-0.015(0.004)^{* * *}$ & $-0.016(0.004)^{* * *}$ \\
B to C, lagged actual & & $0.026(0.016)$ & $-0.015(0.004)^{* * *}$ \\
Female & & & $0.711(0.446)$ \\
Age & & & $0.056(0.093)$ \\
White & & & $0.776(0.456)$ \\
Working & $1.124(0.393)^{* *}$ & $1.088(0.381)^{* *}$ & $-0.226(0.488)$ \\
Constant & 0.0411 & 0.0425 & 0.0425 \\
\hline $\mathrm{R}^{2}-$ within & 0.1392 & 0.1336 & 0.2060 \\
$\mathrm{R}^{2}-$ between & 0.1040 & 0.1009 & 0.1472 \\
$\mathrm{R}^{2}-$ overall & $93.15(0.00)$ & $96.29(0.00)$ & $102.55(0.00)$ \\
Wald $\chi^{2}\left(\right.$ Prob $\left.>\chi^{2}\right)$ & ${ }^{* *} \mathrm{p} \leq 0.01$ & &
\end{tabular}

Notes: This extends Table 3, in text. 2001 observations, 69 groups, 29 observations per group. The first period is omitted in column (1) for consistency with columns (2) and (3). Marginal effects shown, standard errors in parentheses. A Hausman test on column 1 fails to reject the hypothesis that the coefficients are consistent $\left(\chi^{2}=1.59\right.$, Prob $\left.>\chi^{2}=0.81\right)$. 